\title{
العلاقة بين فعالية أداء مديري المدارس والحصول على الرخصة المهنية ****ةراسة استطلاعية على المدارس القطرية
}

\section{عبدالله ابو تينة}

كلية التربية- جامعة قطر

حمده السليطي

وزارة التعليم والتعليم العالي ( مثليطي
حصه صادق

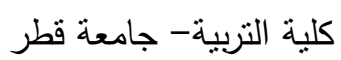

فاطمة المطاوعة

كلية التربية- جامعة قطر

\section{ملخص الاراسة}

استهدفت هذه الدراسة بحث العلاقة بين حصول مديري المدارس في قطر على رخصة

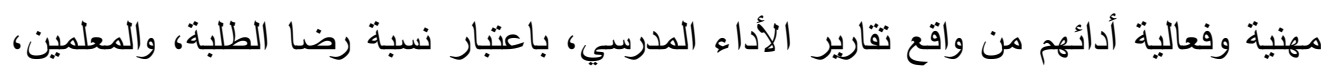
وأولياء الأمور عن المدرسة التي يعمل فيها مدير المدرسة مؤشراً على فعالية أدائه.

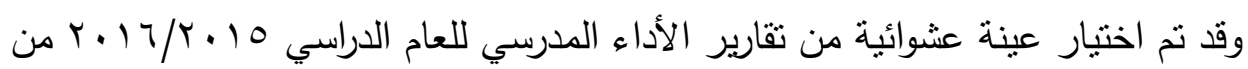

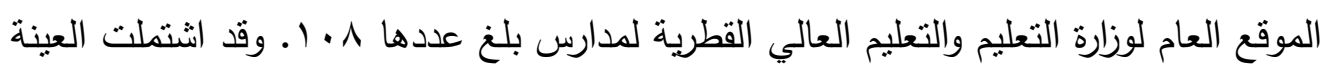

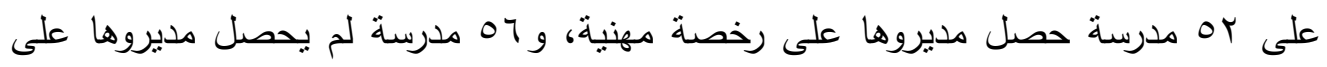
رخصة مهنية.

وأظهر تحليل النتائج عدم وجود فروق ذات دلالة إحصائية لرضا الطلبة عن أداء المدرسة يعزى إلى حصول المدير على رخصة مهنية، بينما ظهرت فروق ذات دلالة إحصائية

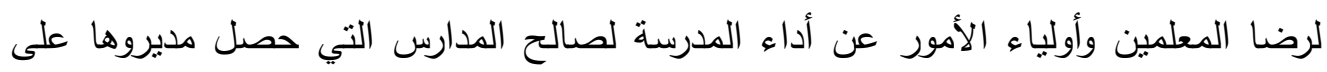
رخصة مهنية.

وقد انتهت الدراسة إلى مجموعة من المقترحات والتوصيات لتطوير نظام الرخص المهنية

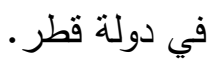

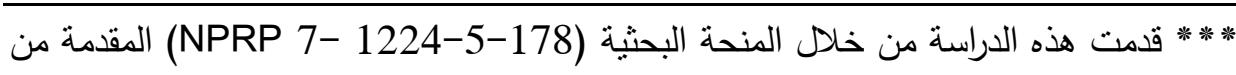
الصندوق القطري لرعاية البحث العلمي (عضو في مؤسسة قطر ). 


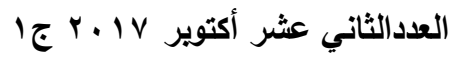

THE RELATIONSHIP BETWEEN SCHOOL LEADER'S

EFFECTIVENESS AND OBTAINING THE PROFESSIONAL LICENSES: AN EXPLORATORY STUDY ON QATARI SCHOOLS

HISSA SADIQ

ABDULLAH ABU-TINEH

FATMA AL-MUTAWAH

Qatar University

HAMDA AL-SULATIE

Ministry of Education \&Higher Education

ABSTRACT_ The purpose of the study was to examine the relationship between obtaining the professional licenses and effective performance of school leaders as identified by school performance reports. It was assumed that students, teachers, and parents' levels of satisfaction in school reports are indicators of school leader's effectiveness. Data was gathered from 108 school performance reports as published by Ministry of Education \& Higher Education for the year 2015-2016. School leaders in 52 participating schools obtained the professional licenses while school leaders in 56 participating schools have no professional licenses. Percentages, standard deviations, and ttests were used to analyze the data. Results showed that no statistical differences were found in students' satisfaction between the two school types. However, there were statistical differences in parents and teachers' satisfaction in the two school types attributed to obtaining the professional license. Teachers and parents of students in schools run by licensed school leaders satisfied more than schools run by unlicensed school leaders. Finally, many recommendations and implications were discussed and proposed. 


\section{1. المقدمة}

شهد النظام التعليمي القطري مع بداية القرن الحادي والعشرين حركة إصلاح تعليمي

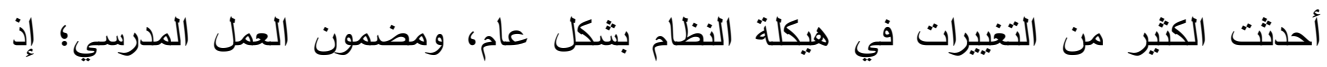

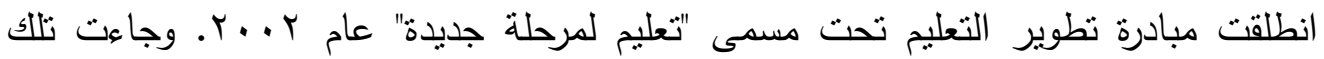
المبادرة بعد دراسة تقييمية للنظام التعليمي الذي كان يواجه العديد من التحديات، من أبرزها المركزية الثديدة في الإدارة التي كانت تحد من دور مدير المدرسة كقائد تعليمي. ولقد التزمت قبادات دولة قطر ببناء نظام تعليمي على مستوى عالمي إيماناً منها بأن دأن

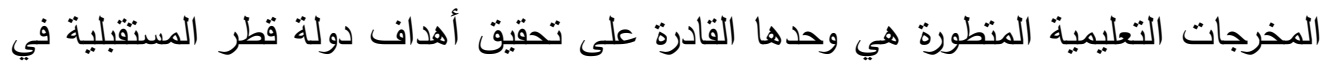

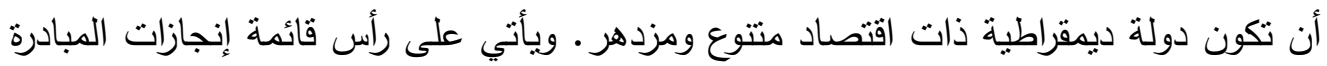

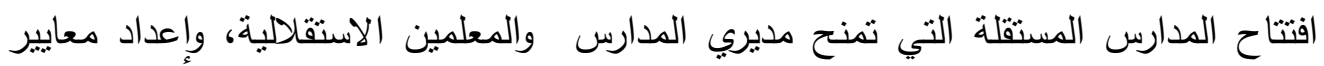
للمناهج مبنية على معايير دولية، وتطوير نظم تقييم شاملة لرصد التطور، وتحديث نظام

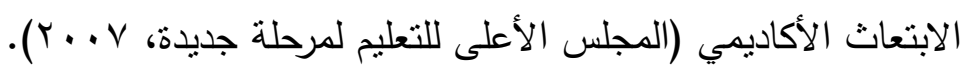

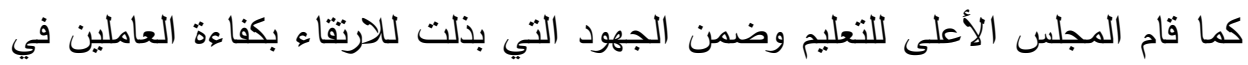

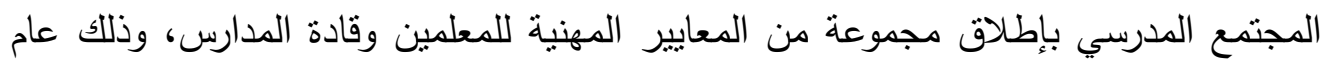

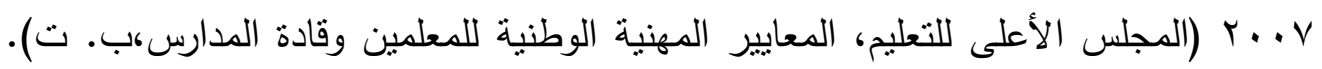
تلى ذلك إنثاء مكتب للرخص المهنية وهو الجهة المختصة بمنح تراخيص العمل المهني للمعلمين وقادة المدارس.

وتهدف المعايير المهنية الوطنية إلى إيجاد مرجعية مشتركة لتوصيف الأعمال التي يقوم

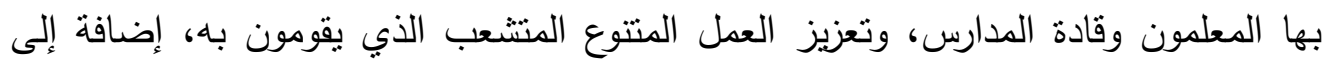
تقديم الدعم لهم أثناء عملهم في مدارسهم. وتصف هذه المعايير الإجراءات والأمور التي ينبغي على المعلمين وقادة المدارس

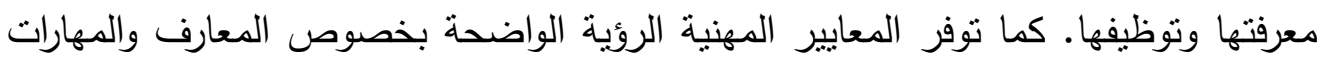

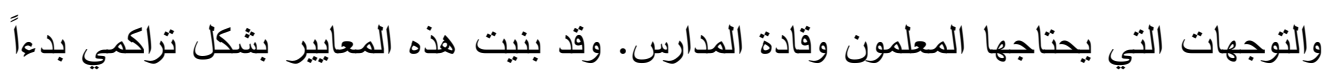

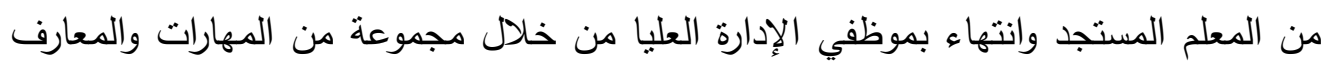
والتوجهات التي ينبغي على تلك الفئات تمثلها وتتفيذها وتقييمها، من أجل التحقق من فاعليتها في تحقيق الأهداف المرجوة (المجلس الأعلى للتعليم، المعايير المهنية الوطنية للمعلمين وقادة المدارس في دولة قطر ، ب.ت). 
وفي ضوء ذللك كله تغيرت معايير اختيار مديري المدارس القطرية وإجراءات تقييم أدائهم، فبعد أن كانت الأقدمية في العمل أكثر المعايير المعتمدة لترقية المعلمين إلى مديري

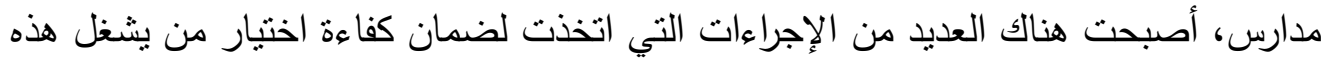
الوظائف الإدارية، واستبقائهم في العمل، كضرورة حضور برامج تدريبية معينة واجتياز مقابلة

شخصية ثم الحصول على الرخصة المرنية.

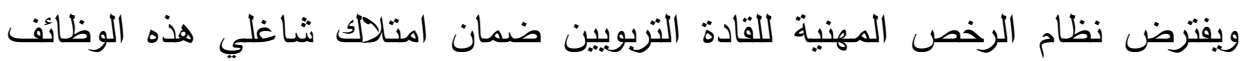

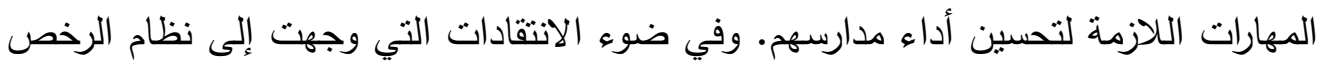
المهنية في دولة قطر وفاعليته جاءت هذه الدراسة للبحث في العلاقة بين حصول مديري المدارس القطرية على الرخصة المهنية وفعالية أدائهم المدرسي. r. - r مشكلة الدراسة

في ضوء مبادرة تطوير التعليم أصبحت المدرسة وحدة أساسية تلعب دوراً محورياً في تطوير التعليم، ومنحت الاستقلال الإداري والمالي، وأصبح منوقعا منها انتهاج سياسة تطويرية

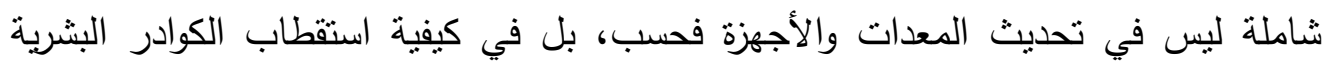
والوطنية والاحتفاظ بها وتطويرها. ويقع على صاحب نرخيص المدرسة وهيئتها التدريسية

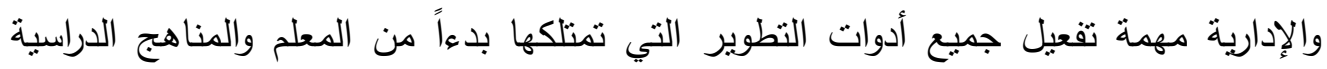

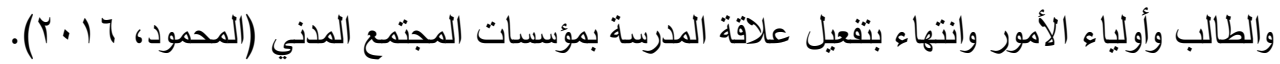
ولقد جاء تطوير المجلس الأعلى للتعليم للمعايير المهنية للمعلمين وقادة المدارس ولنظام

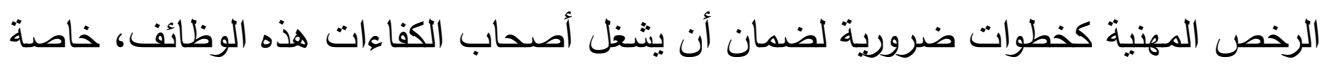
وأن تحقيق أهداف مبادرة تطوير التعليم يستلزم وجود قيادات تعليمية متميزة على مستوى فئل المعلمين أو قادة المدارس.

وعلى الرغم من أن نظام الرخص المهنية كان يقوم على فلسفة مؤداها أن الحاصل على ألى

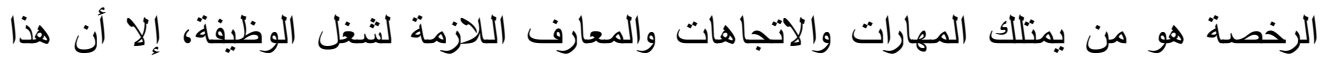
النظام قد واجه العديد من الانتقادات منذ بداية تأسيسه. ولقد أثنارت إحدى الدراسات التي أجريت على نظام الرخص المهنية في دولة قطر

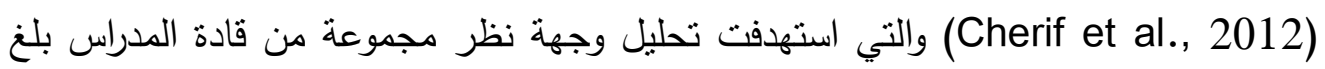

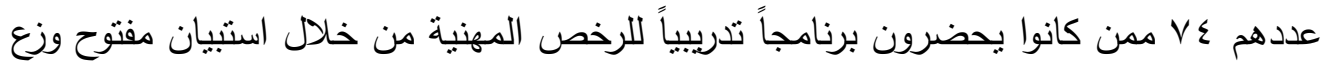

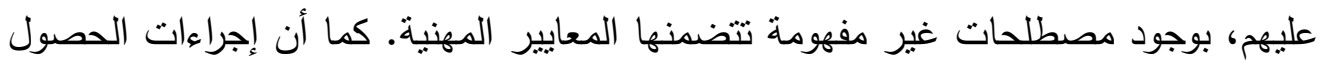
على الرخصة صعبة، إضافة إلى تجاهل وجهات نظر قادة المدارس عند وضع هذا هذا النظام. 
كما أثنارت دراسة أخرى (صادق وآخرون، 17 (ب) حول واقع نظام الرخص المهنية للمعلمين في دولة قطر إلى أن أهم التحديات التي تواجه النظام هو عدم احتساب سنوات آترات

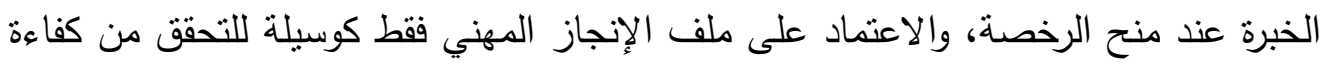

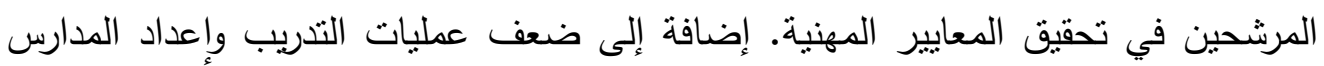
على عمليات التصديق، وصعوبة فهم المعايير المهنية، وعدم ارتباط نظام الرخص المهنية بنظام التقييم. وهذا قد يؤدي إلى إخفاق بعض المرشحين في الحصول على الرخصة المهنية

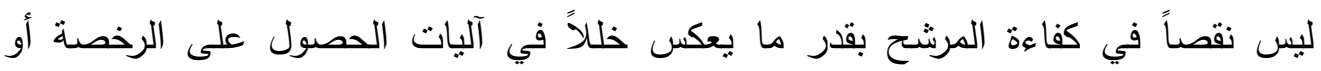
غموض في المعايير المهنية. ووفق علم الباحثين فلا توجد دراسة سابقة حاولت البحث في العلاقة بين الحصول على في الرخصة المهنية في دولة قطر وفعالية أداء مديري الددارس. لذا فإن مشكلة الدراسة الحالية

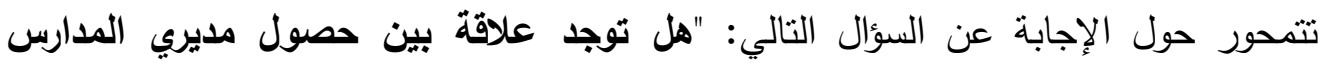

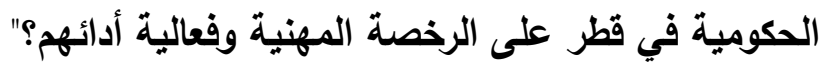

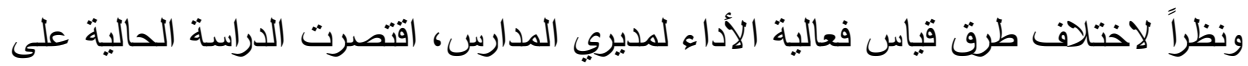
الاستدلال على فعالية الأداء بقياس نسبة رضا الطلبة والمعلمين وأولباء الأمور عن أداء المدرسة. وتمت الإجابة عن السؤال الرئيسي للاراسة من خلال محاولة الإجابة على الأسئلة الفرعية التالية: 1- هل توجد علاقة بين حصول مديري المدارس الحكومية في قطر على الرخصة المهنية ورضا الطلبة عن المدرسة؟ ץ- هل توجد علاقة بين حصول مديري الددارس الحكومية في قطر على الرخصة المهنية

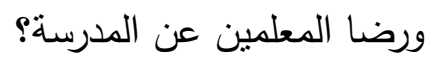
r-هل توجد علاقة بين حصول مديري المدارس الحكومية في قطر على الرخصة المهنية

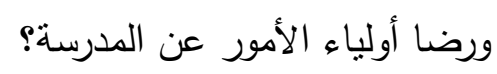
r. أهداف الاراسة وأهميتها هدفت الدراسة تحقيق ما يلي:

- التعريف بالمعايير المهنية الوطنية لقادة المدارسة وآليات الحصول على الرخصة المهنية. - دراسة طبيعة العلاقة بين حصول مديري المدارس الحكومية على الرخصة المهنية وفعالية

- الخروج بتوصيات ومقترحات من شأنها نطوير نظام الرخص المهنية في دولة قطر . 


\section{ع. ـ الإطار النظري للاراسة}

ينقسم الإطار النظري لهذه الدراسة إلى جزأين، يتتاول الجزء الأول منها فعالية أداء مديري المدارس وعلاقة ذللك بنظام الرخص المهنية، ويتتاول الجزء الثاني المعايير المهنية القطرية ونظام الرخص المهنية.

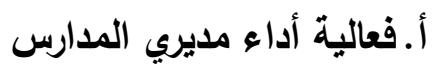

يلعب مديرو المدارس دوراً مهماً في نطوير بيئة تعليمية مناسبة لتعلم الطلبة، وتوفير

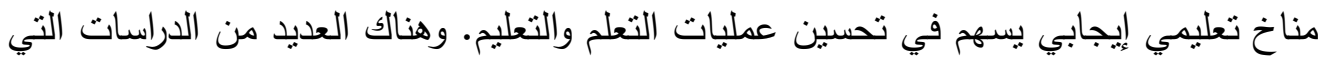
أشارت إلى العلاقة الإيجابية بين فعالية أداء مديري المدارس وتحصيل الطلبة ، ورضا

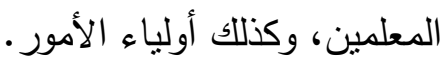
وفي دراسة تحليلية متعمقة قام ديفس وآخرون (Davis et al., 2005) لعديد من برامج إعداد قادة الدارس، وبمراجعة الأدب التربوي المرتبط بها تنين ما يلي داني: وجود إجماع متزايد

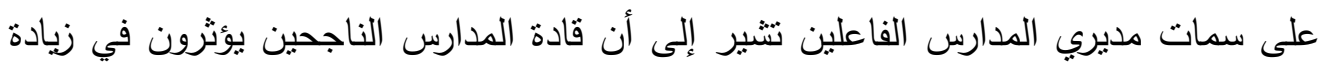
تحصيل الطلبة من خلال طريقتين: - دعم وتعزيز معلمين فاعلين. - تطبيق إدارة تتظيمة فعالة. وهذا يؤثز إيجابا في متطلبات إعداد المديرين وترخيصهم والذي بدوره يوجه إلى ضرورة

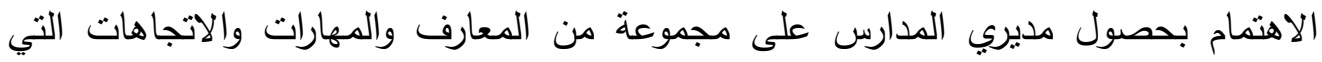
تضمن نجاحهم في عملهم. كما افترضت الدراسات التي خضعت لهمهن للتحليل في هذه الدراسة إلى أن إعداد المديرين

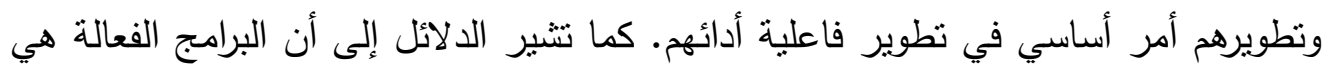
المبنية على أساس البحوث ولها منهج منماسك وتقدم خبرة في سياق عملي واقعي، وتستخدم نظام المجموعات والمشرفين Mentors ومصدمة لتسهيل الأنشطة المشتركة بين برامج الإعداد والمدارس.

ولقد حددت نتائج بحوث ديفس وآخرون (Davis et al., 2005) خلال السنوات الماضية ثلاثة مفاهيم أساسية لعمل مدير المدرسة: - تطوير فهم عميق لكيفية دعم المعلمين. - إدارة المنهج بطريقة تضمن الارتقاء بتعلم التلاميذ. 
- تطوير القدرة على نقل / تحويل المدرس إلى تتظيم أكثر فعالية، والذي من خلاله يمكن أن

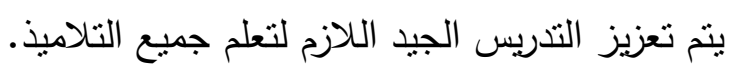

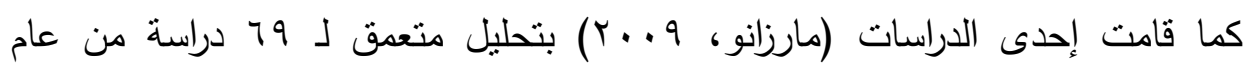

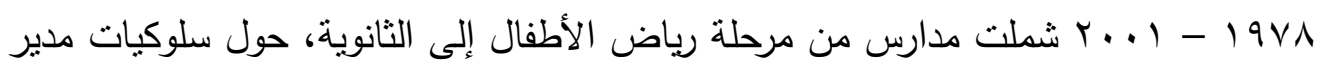

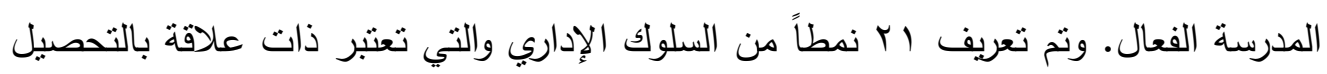
العلمي للطلبة، وهي على النحو التالي: الندال 1-التأكيد، إذ بعتز بالإنجازات ويحتقي بها ويقر بالإخفاقات.

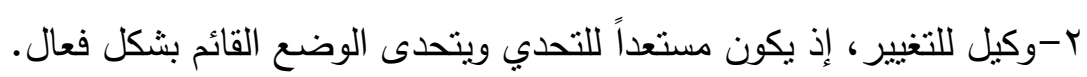
r-المكافآت الطارئة، إذ يقدر الإنجازات الفردية ويكافؤها. ع - التواصل، إذ يقيم خطوط اتصال قوية مع المعلمين والطلبة. ه-الثقافة، إذ بعمل على رعاية المعتقدات المشتركة ومعنى المجتمع والتعاون.

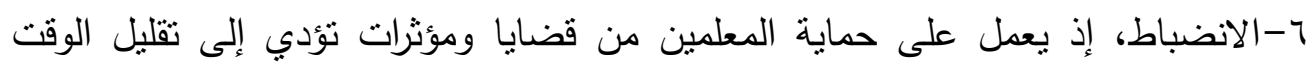
المخصص لإعطاء الدروس أو تقليل تركيزهم.

V- المرونة، إذ يكيف سلوك قيادته على حاجات الوضع الراهن ويبدي عدم الارتياح ازاء الثنقاق.

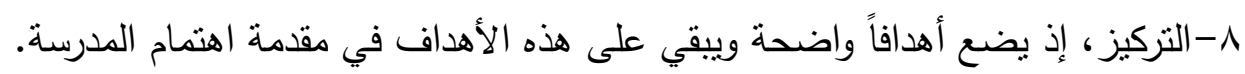

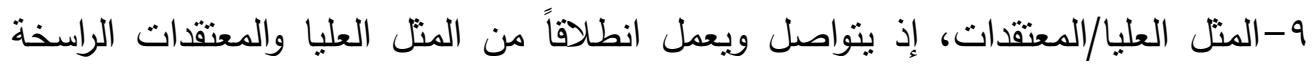

$$
\text { التي تذور حول التعليم. }
$$

• 1- المدخلات، إذ يشرك المعلمين في وضع القرارات والسياسات المهمة وتتفيذها. 11-التحفيز الفكري، إذ بضمن أن الهيئة التدريسية والإدارة مدركة لأهم النظريات والممارسات الراهنة ويجعل من مناقتنها جانبا منتظما لتقافة المدرسة.

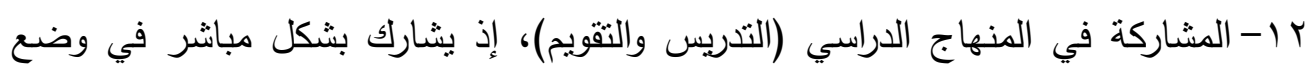
المنهج الدراسي وتطبيقه ويشارك في التدريس والتقويم.

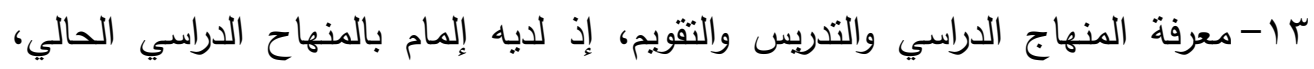
والتدريس وأساليب التقويم.

ع ا - المراقبة/ التقويم، إذ براقب كفاءة أساليب التدريس وتأثيرها في تعلم الطلبة. 10 - الساعي للكمال، إذ بطرح افكاراً نيرة ويقود ابتكارات جديدة ومثثيرة.

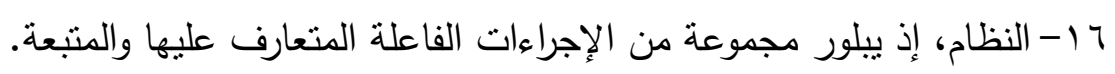


IV

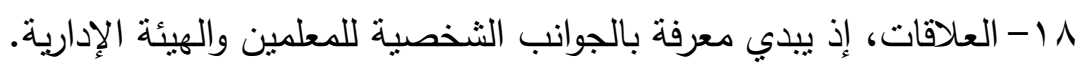
9 1 - الموارد، إذ يزود الأساتذة بالمواد المهنية اللازمة للقيام بوظائفهم بصورة بالب الداجحة.

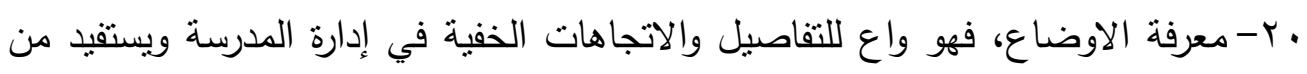
معلوماته في مواجهة المشكلات الراهنة والمحتملة.

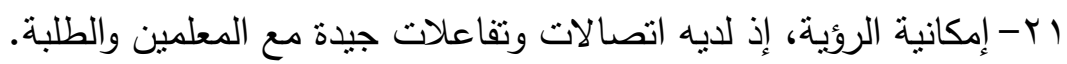
وفي دراسة هدفت تعرف فعالية مديري المدارس (Grissom et al., 2001)

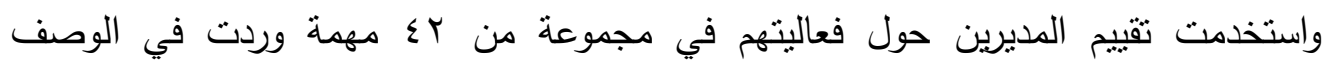

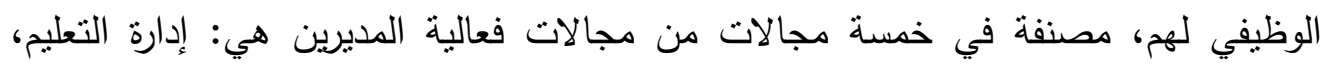

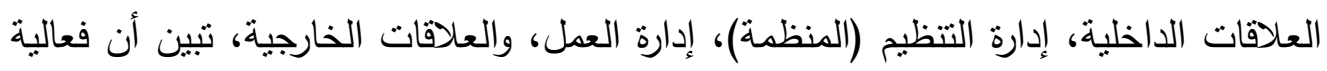

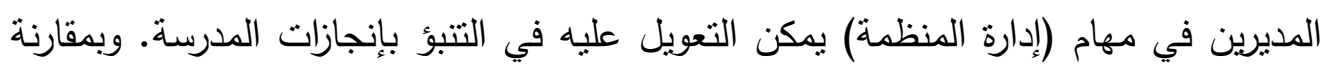

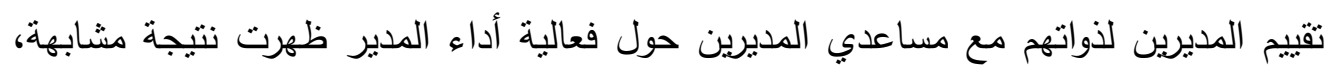
وهي أن الفعالية في إدارة التنظيم (المدرسة) يلعب دوراً رئيسا في نجاح المداعة المدرسة.

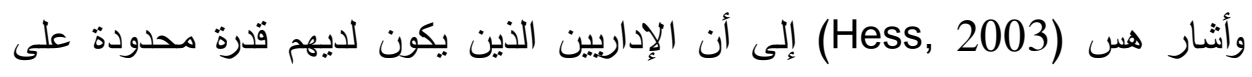

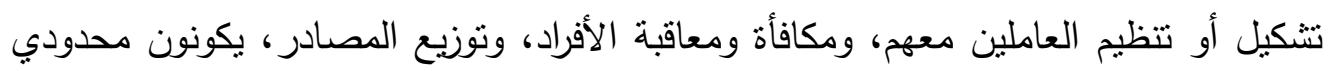

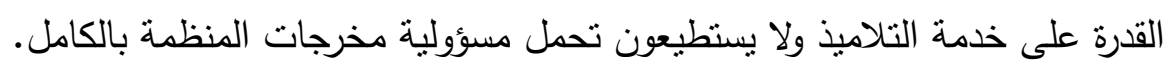

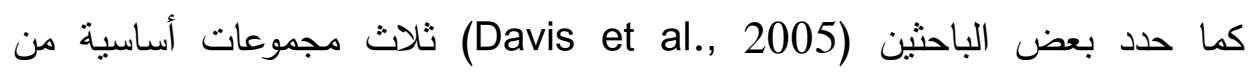
الممارسات المطلوبة للقادة، وهي: - تطوير الأفراد عن طريق تمكينهم من أداء أعمالهم بفعالية، وذلك من خلاد تقديم دعم فكري وعملي لنطوير عملهم بتزويدهم بممارسات مطلوبة.

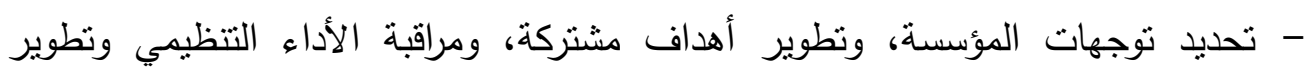

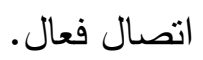
- إعادة تصميم المؤسسة، من خلال بناء نقافة مدرسية منتجة، وتعديل الهيكل التتظيمي الذي يساعد على تفويض العمل وبناء ثقافة العمل المشترك.

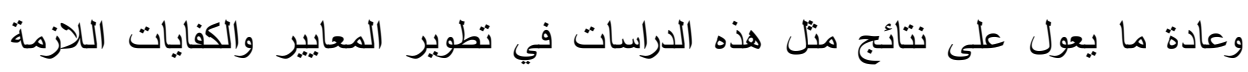

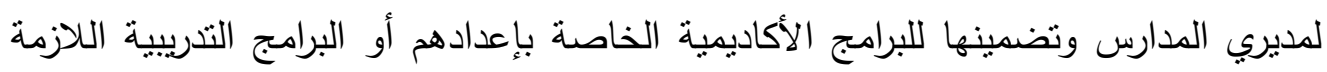

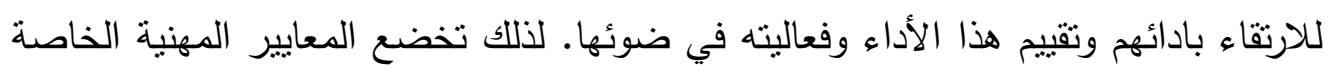

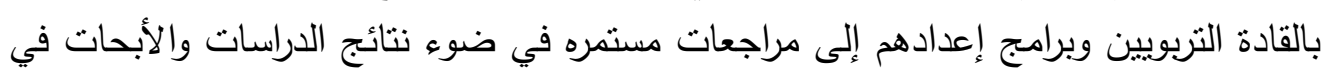
مجال الإدارة التعليمية. 
وعلى الرغم من تتوع الدراسات التي استعرضناها نجد أن أهم المهارات التي يتم التركيز عليها دائما هي قدرة مدير المدرسة على إداره المجتمع المدرسي بشكل عام مما قد يؤثر إيجاباً على إنجازات المدرسة ويحقق نوعاً من الرضا لدى الطلبة والمعلمين والمجتمع الخارجي. ب. الرخص المهنية وفعالية أداء المديرين

ظهرت في السبعينيات من القرن الماضي العديد من الانتقادات التي وجهت لمديري المدارس ومشرفي المناطق التعليمية لعدم اهتمامهم بجودة التعليم. وقد طالت الانتقادات البرامج

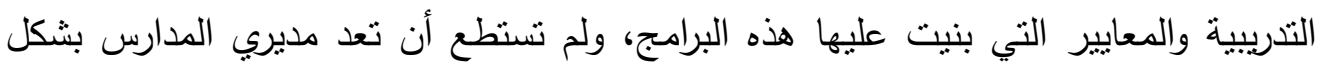

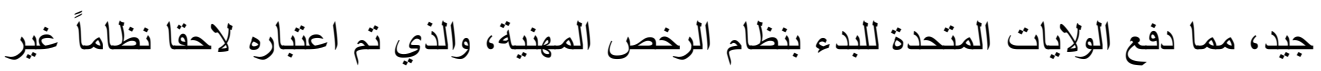

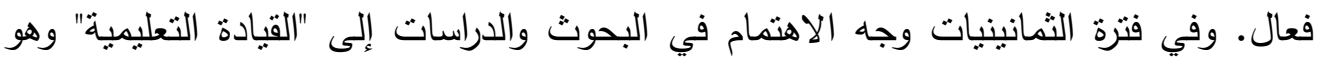
مصطلح يشير إلى قائد المدرسة الذي يدعم الثقافة التي تركز على صميم عمليتي النعليم

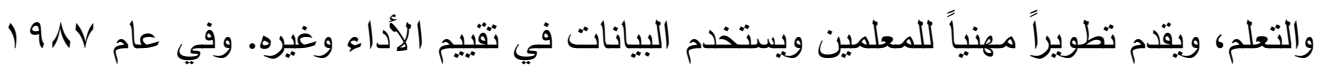
كان هناك قلق أيضا حول فعالية القيادة المدرسية، لذا اوصى المجلس الوطني للتميز في

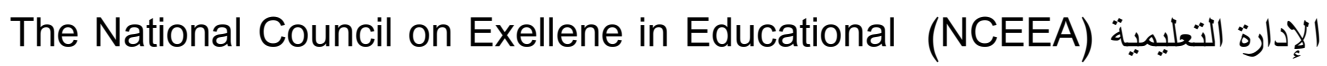
بالعديد من الإصلاحات من بينها خفض عدد برامج إعداد الإداريين، Administration)

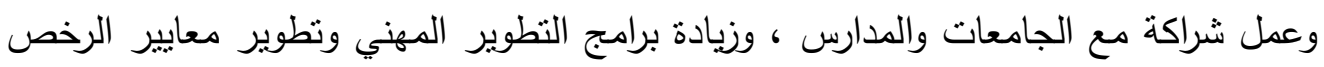
المهنية. وفي عام 1997 تم تطوير المعايير المهنية لقادة المدارس (Hess, 2003). ويتطلب حصول مدير المدرسة في أمريكا على رخصة مهنية أن تكون لديه على الأقل ثلاث سنوات من خبرة التدريس في التعليم العام، وأن يكون قد أنهى برنامجا معتمدا في الإدارة التعليمية، وحصل على تدريب ميداني. كما يتطلب الأمر في العديد من الولايات المتحدة ولني

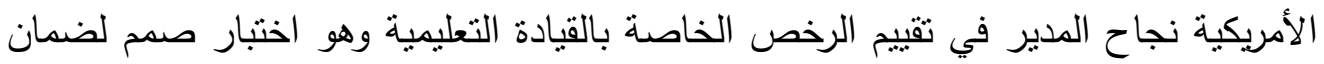
امتلاك المرشح للقيم والاتجاهات المقبولة والمقرة مهنيا (Hess, 2003).

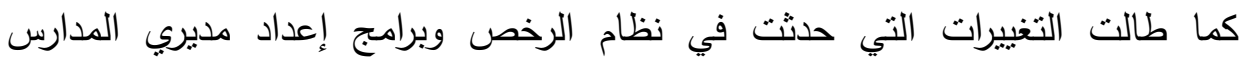

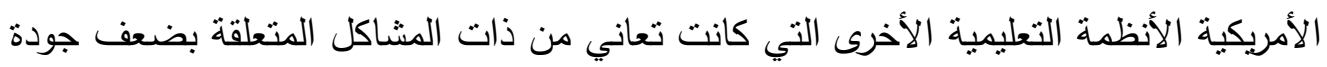

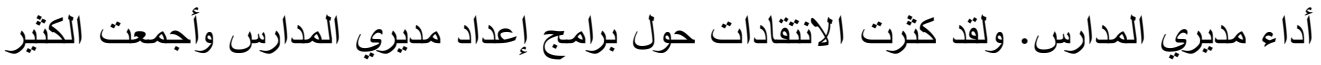

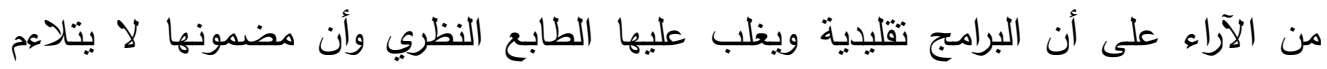

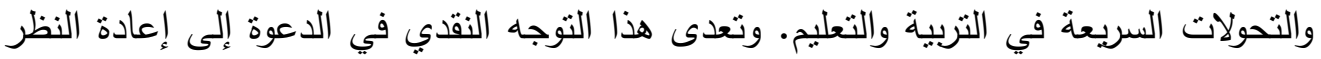

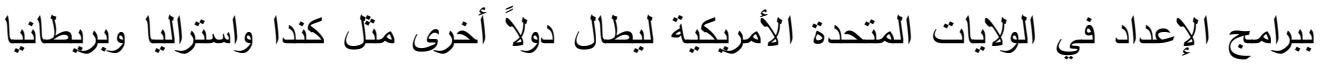


وفرنسا. وإزاء ذللك قامت مبادرات في كل من هذه الدول هدفها إصلاح وتجديد برامج الإعداد والتطوير الاداري للمدارس. ففي كندا على سبيل المثال تم إنشاء مركز لتطوير القيادة المدرسية هنية

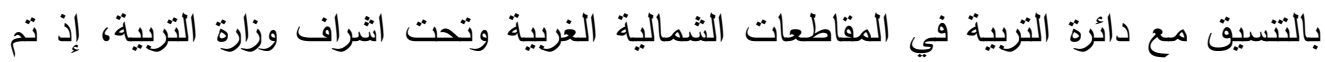

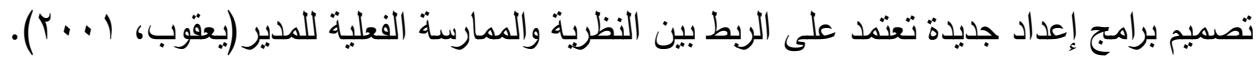

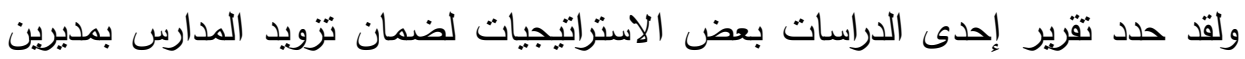

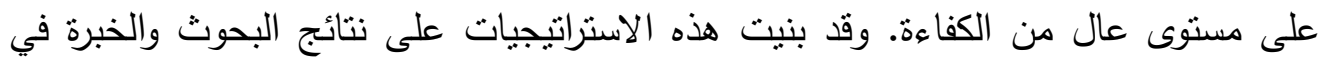

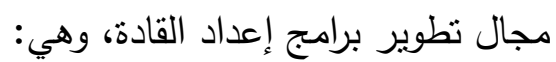

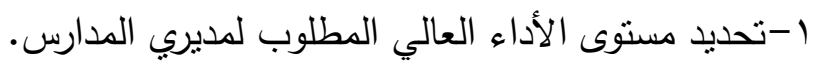
r-إعادة تقويم برامج إعداد مديري المدارس.

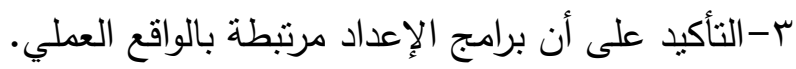

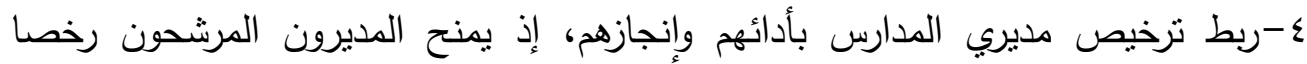

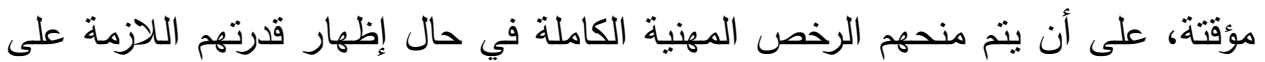
تطوير المدرسة وتطوير الممارسات التدريسية وتطوير إنجاز الطلبة. 0-ترقية المعلمين عالي الكفاءة إلى وظيفة ددير مدرسة من خلال مسارات إعداد غير تقليدية. 7- تكوين فرق أكاديمية مركزية لتطوير فرق القيادة المدرسية داخل المدرسة.(Bottoms et al., 2005)

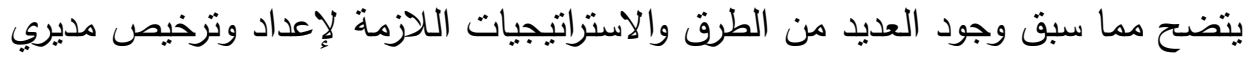
المدارس، تعرض بعضها للانتقاد لضعفها في إعداد قادة على مستوى عال من الكفاءة. كما لعاديا

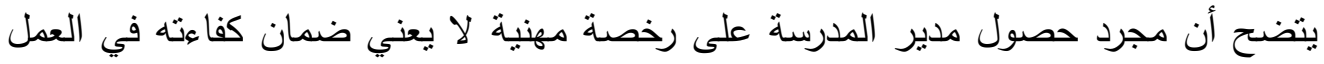
وذللك للقصور الذي قد يعتري هذا النظام سواء ما يتعلق بالمعايير في حد ذاتها أو في آليات الحصول على الرخصة.

\section{ج. قياس فعالية أداء مدير المدرسة}

لا يسنطيع أحد أن ينكر الدور المهم الذي يقوم به مدايه مدير المدرسة في توجيه جهود

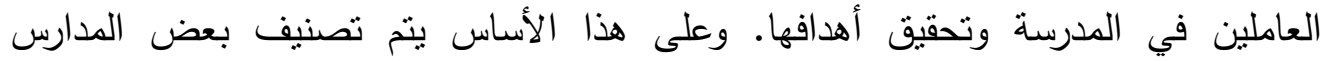

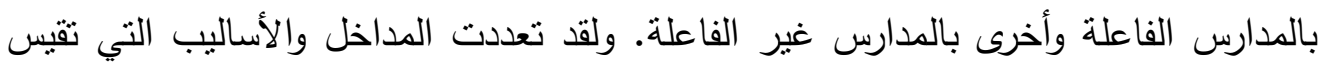

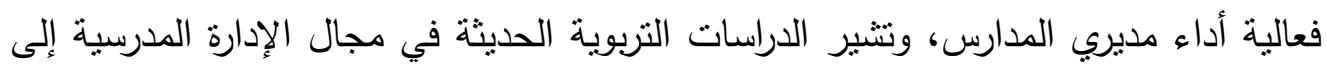

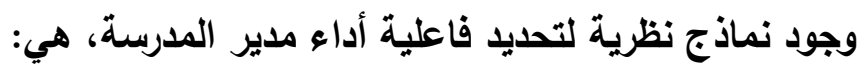

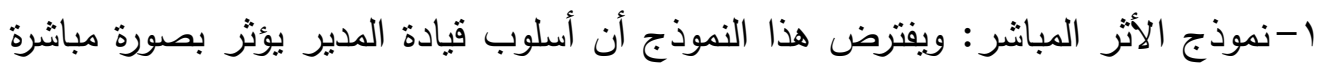

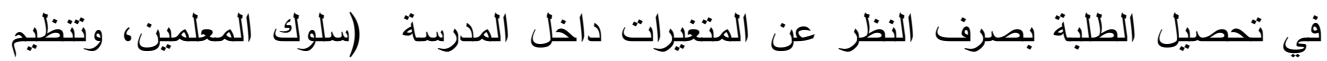
المنهج، وثقافة الددرسة...الخ). 
r-نموذج المتغيرات المطلقة: ويقوم هذا الافتراض على أساس أن العوامل الاقتصادية

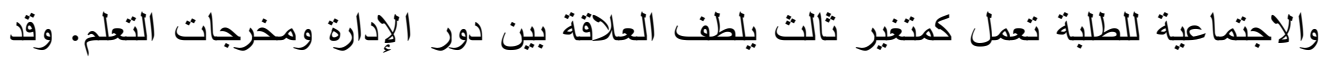
يؤدي المدير ضمن هذا النموذج دور المتغير المستقل فقط، أي الثخص المئه المؤثر في العلاقة

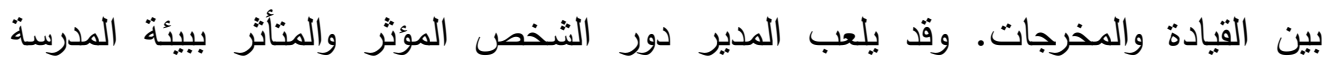
ومتغيراتها في الوقت نفسه. كما أن هذه العوامل قد تؤثر في تحصيل الطلبة بصورة مباشرة أو لون غير مباشرة (عبر سلوك المعلم مثنلا). r-نموذج المتغيرات الوسيطة: وتفترض هذه المقاربة أن الأثر الذي يحدثه المدير في

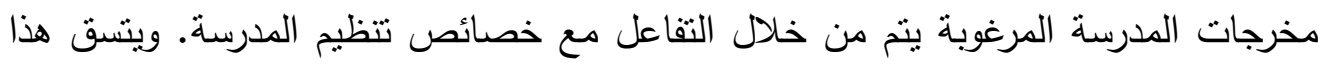
التصور مع القول بأن المديرين يحققون النتائج من خلال الأشخاص الآخرين.

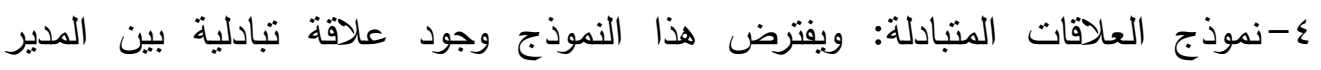
وخصائص المدرسة، فالمدير قد يحدث تغييرات تؤدي بدورها إلى تأثنرات منبادلة في المتغيرات

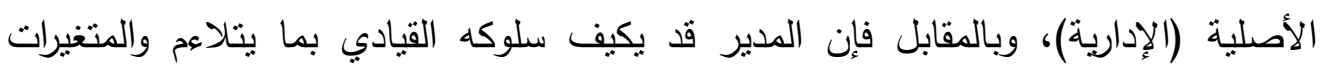
الطارئة على مخرجات المدرسة. وبالرغم من تعدد النماذج التي تربط بين فعالية أداء المدير

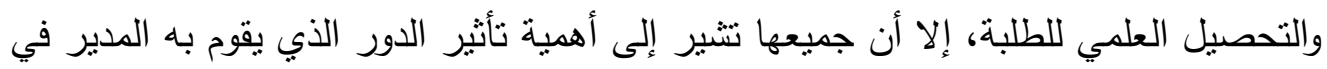
كل تفاصيل العمل المدرسي، وأهمية دوره المباشر وغير المباشر في تطوير بيئة تعليم وتعلم

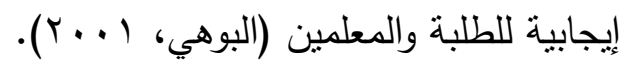
ولعل الافتراض الذي تقوم عليه هذه الدراسة هو الأقرب للنموذج الثالث، إذ تؤثز المعايير

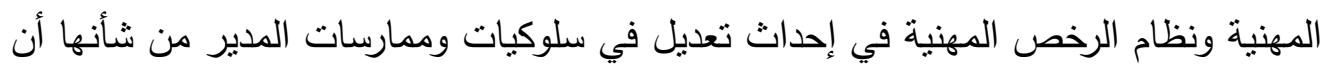

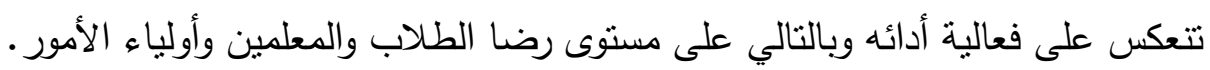
د. نظام الرخص المهنية لمديري المدارس في قطر فئه

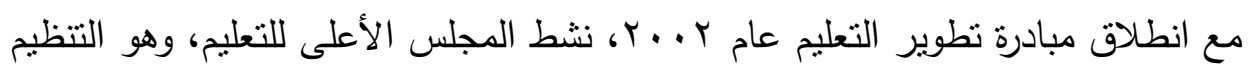

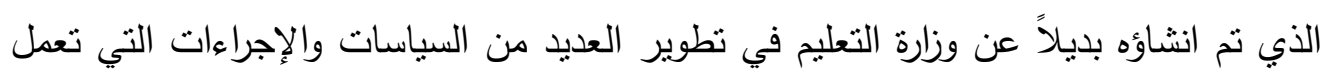
على تطوير جودة التعليم. ومن ضمن هذه الإجراءات ضرورة حصول المعلمين وقادة المدارس على رخص مهنية. وتبنى هذه الرخص على المعايير المهنية الوطنية التي تم إطلاقها عام

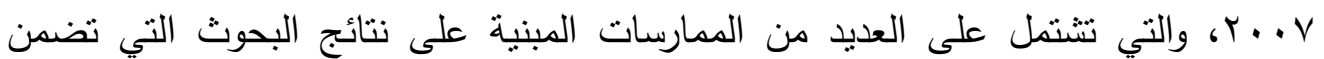
فعالية أداء المعلمين وقادة المدارس. 
وتتألف المعايير المهنية الوطنية لقادة المدارس من سبعة معايير تؤطر مسيرتهم المهنية، وتتتاول هذه المعايير المتطلبات الأساسية التي ينبغي توافرها في قادة المدارس الحكومية، وينقسم قادة المدارس إلى فئتنين هما: - شاغلو المناصب الإدارية العليا في الددارس الحكومية مثل أصحاب التراخيص ومديري

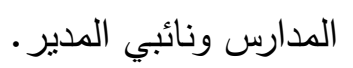

- شاغلو الإدارة الوسطى ويشمل ذلك الموظفين الآخرين ممن يشغلون مسؤوليات معينة في

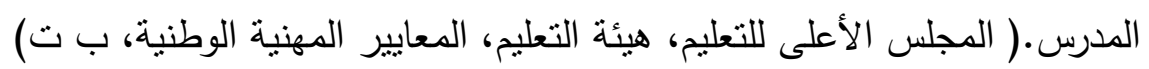

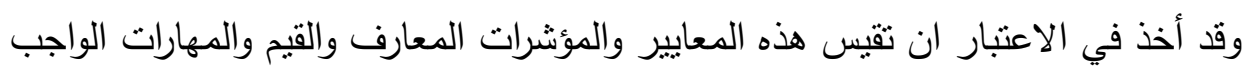

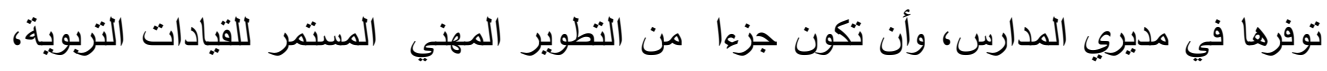
وأن تسهم في تسليط الضوء على المهارات المهنية التي تتضمن العلاقات التفاعلية في البيئة

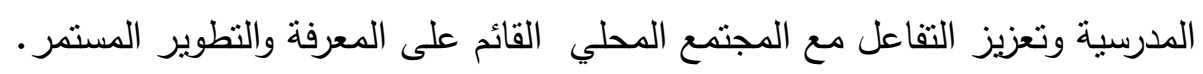
- - وتتثمل هذه المعايير سبعة معايير رئيسة متفرعة إلى العديد من المعايير الفرعية، وعلى الفئي النحو التالي:

1-قيادة التعليم والتعلم في المجتمع المدرسي وإدارتها، ويتضمن المعايير الفرعية التالية: - تهيئة بيئة تعلم آمنة ومثمرة ومثيرة للتحدي.

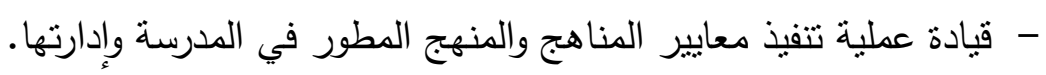
- تشجيع عمليات تعليم وتعلم وتقييم عالي الجودة. - متابعة جودة برامج التعليم والتعلم وتقييمها.

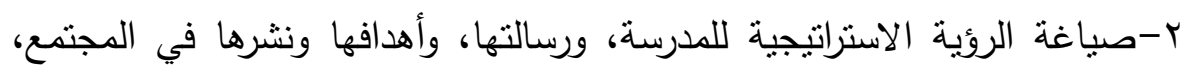
وتتضمن: - قيادة عملية نطوير صياغة الروئية الاستراتجية والأهداف الخاصة بالمدرسة وإدارتها. - إثراك مجلس الآباء في عمليات إعداد الرؤية الاستراتيجية والأهداف الخاصة

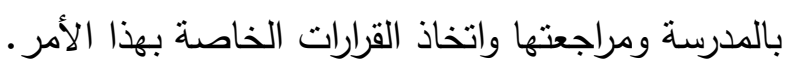
- نشر الروية الاستراتيجية والأهداف للمجتمع المدرسي وترويجها.

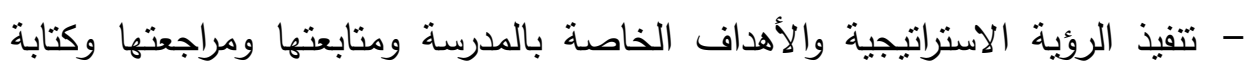

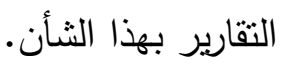


r-قيادة التغيير وإدارته ويتضمن:

- قيادة مجتمع المدرسة في التخطيط لإدخال التغيير وتسهيل إحداثه.

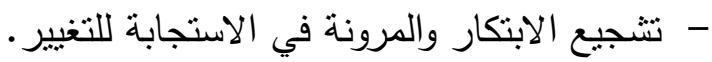
- إدارة التحديات والفرص المستجدة. - الاستجابة لمبادرة تطوير التعليم التي يتبناها المجلس الأعلى للتعليم في دولة قطر . ع-قيادة الأفراد والفرق وتطويرهم، وتتضمن: - تقديم قدوة في المعايير العالية الأداء. - تطوير الأفراد والفرق وتمكينهم ودعهم.

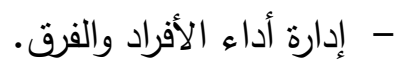
- - إنشاء شبكات لدعم الأفراد والفرق. 0-تطوير العلاقات بين المدرسة والمجتمع وإدارتها: - بناء علاقات إيجابية مع الأسر لتعزيز تعلم الطلبة. - تأسيس علاقات شراكة بين المجتمع والمدرسة لتعزيز تعلم الطلبة. - التواصل بشكل فاعل مع المجتمع والمدرسة. צ- إعداد الموارد وإدارتها:

- تخصيص الموارد اللازمة لتهيئة بيئة تعلم فاعلة والمحافظة عليها. - - إدارة الموارد البشرية لتهيئة بيئة تعلم فاعلة والحافظة عليها. - - إدارة الموارد المالية لتهئة بيئة تعلم فاعلة والمحافظة عليها.

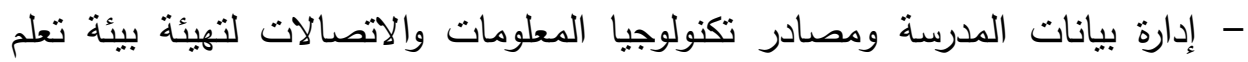
فاعلة والمحافظة عليها.

- إدارة مرافق المدرسة وممتلكاتها لتهيئة بيئة تعلم فاعلة والمحافظة عليها.

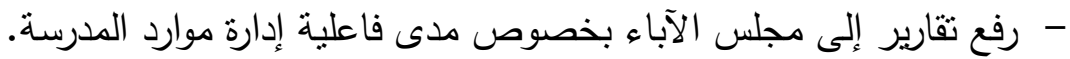
V - التطوير في القيادة والإدارة وتقييمهما وتحسينهما. - قيادة عملية تقييم أداء المدرسة. - تقديم نموذج لتقافة تطوير الأداء الثخصي وأدئة أنداء الزملاء والتعلم مدى الحياة. - المساهمة في مجتمعات التعلم والثبكات المهنية الأخرى.

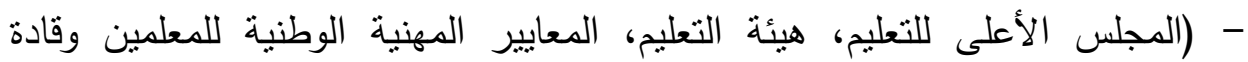

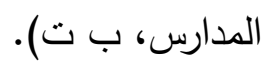


هـ. آلية الحصول على الرخصة المهنية

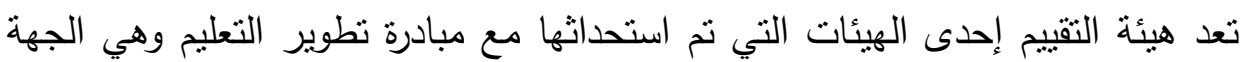
الرسمية المسؤولة عن تقييم أداء المدارس. ومع الإعلان عن معايير الهيئة للمعلمين وقادة فئنة

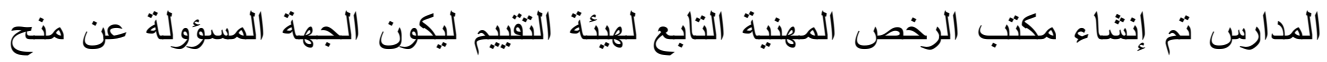
وتجديد الرخص المهنية للمعلمين وقادة المدارس.

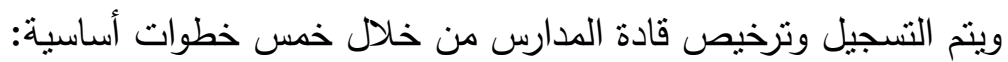
1-التسجيل في نظام الرخص: وتساعد هذه الخطوة على التأكد من المؤهلات العلمية التي حملها المرشح. r-الرخصة المؤقتة: فبعد اعتماد المرشح يتم منحه رخصة مؤقتة.

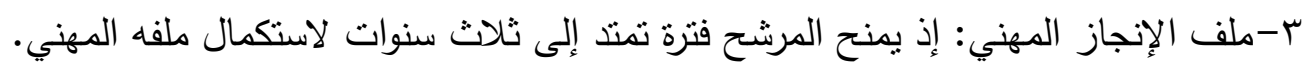
ع-تقارير التقييم: والذب يتضمن أحدث تقييمات سنوية للقائد. ه-أدلة على المؤهلات المهنية والتعلم: ويتضمن هذا الجزء الأدلة ذات الصلة بوظيفة القائد المدرسي في السنوات الثناث الأخيرة.

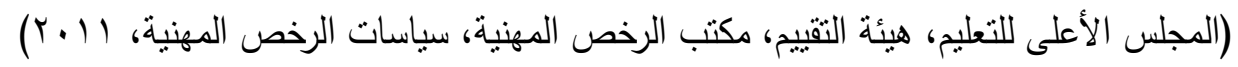
و. خطوات الحصول على الرخصة المهنية الكاملة:

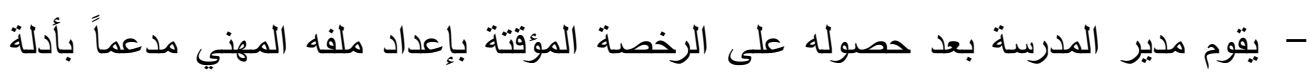
على ممارسته المهنية، وفقا لمعايير قادة المدارس. - يتم عرض الملف المهني على لجنة التصديق المحايدة. - تجري لجنة التصديق المحايدة مقابلة مع المرشح لمناقثة الملف المهني. - توصي اللجنة مكتب الرخص باستحقاق أو عدم استحقاق المرشح للرخصة.

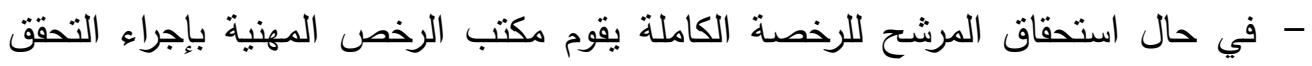

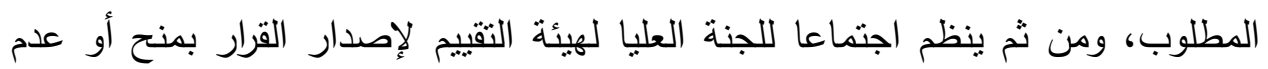

$$
\text { منح الرخصة الكاملة. }
$$

- يقوم مكتب الرخص المهنية باخطار المتقدم بقرار اللجنة العليا لهيئة التقييم.

$$
\text { (المجلس الاعلى للتعليم، هيئة التقبيم، سياسات الرخص المهنية) }
$$

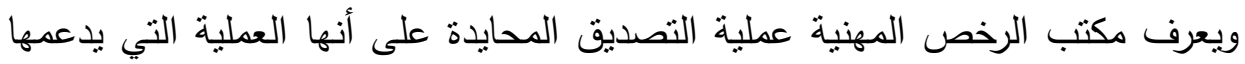
مكتب الرخص المهنية لتقييم كفاءة قادة المدارس وفقاً لمعايير الهيئة الوطنية بهدف ضمانية الهمان

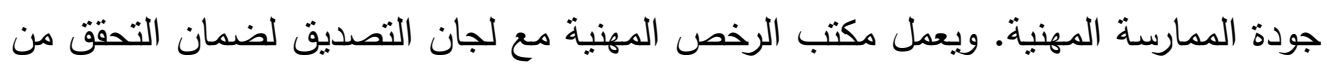

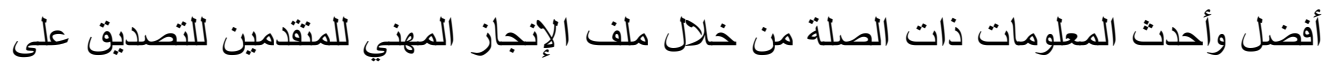




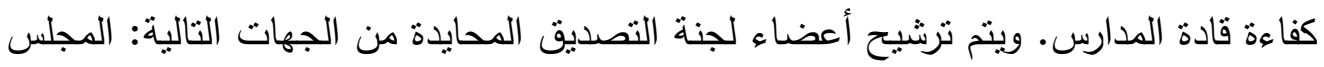

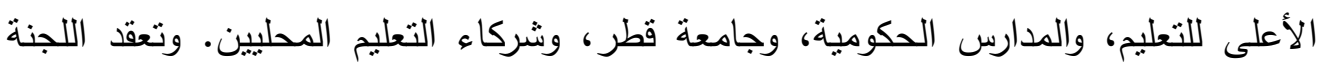

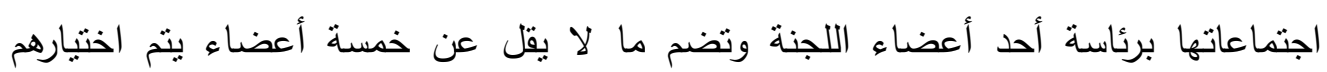
وترشيحهم من قبل مكتب الرخص المهنية.

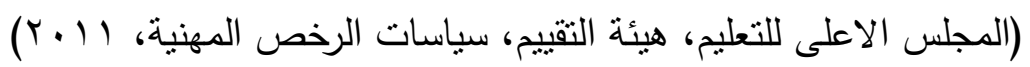

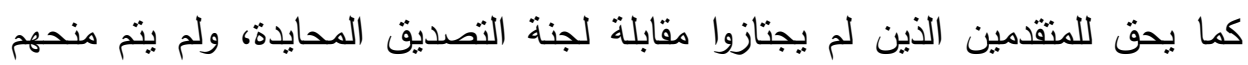
الرخصة المهنية، التقدم بتظلم إلى لجنة التظلمات وفق الآلية التالية:

- - يرفع المنظلم طلب النظلم من خلال اللجنة المحايدة إلى مكتب الرخص الته المهنية. - يرفع مكتب الرخص المهنية طلب النظلم إلى رئيس لجنة التظلمات مرفقاً بكافة الوثائق المطلوبة.

- تدرس لجنة التظلمات طلب التظلم وتعقد اجتماعات لمناقشة أسباب النظلم.

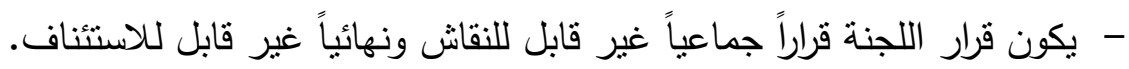

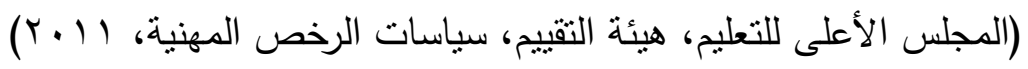

ز. كيف يتم قياس فعالية أداء مدير المدارس في قطر؟

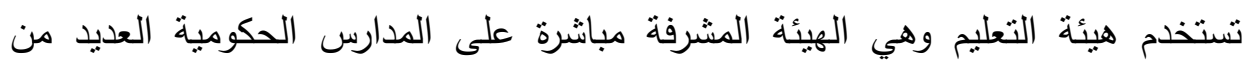

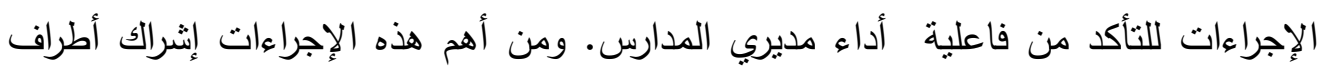

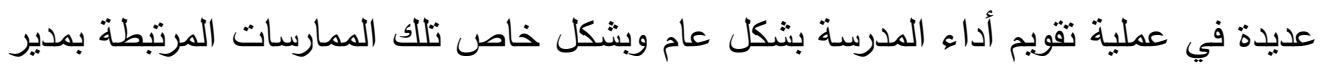

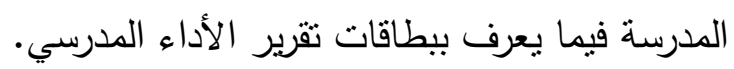
ح. بطاقات تقرير الأداء المدرسي بـاني قبل انطلاق مبادرة تطوير التعليم في قطر ، توفرت فرص فرص محدودة للطلبة وأولياء الأمور

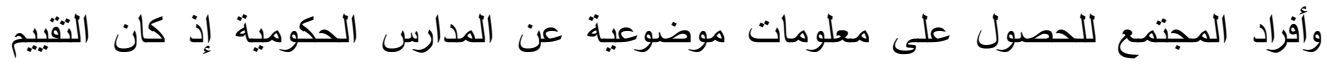

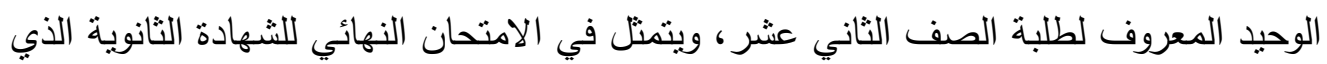

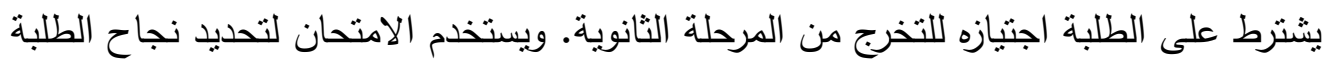

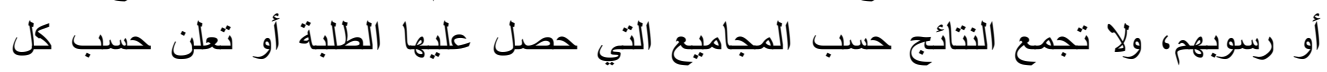

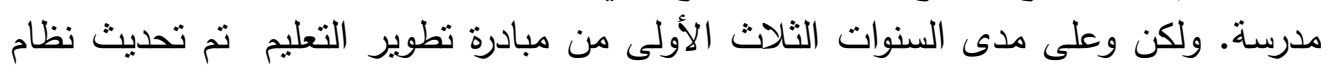

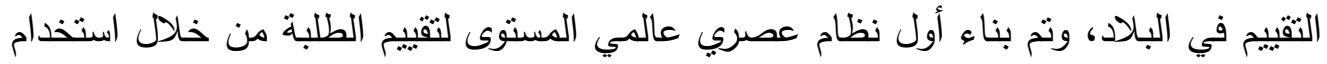

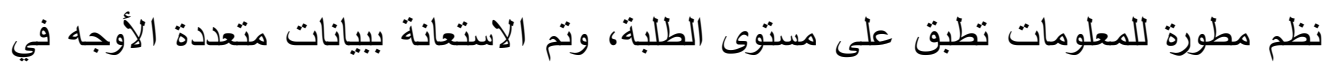

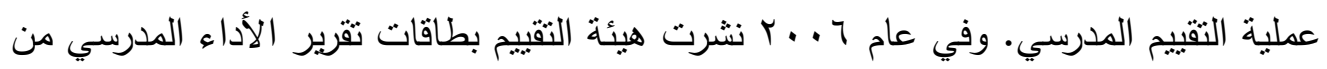

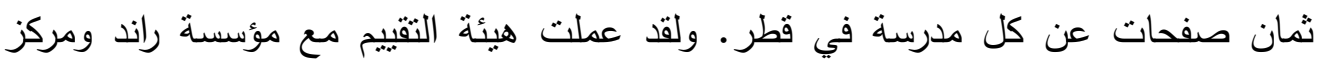


بحوث (NORC) في جامعة شيكاغو على بناء نظام طموح للاستطلاعات السنوية، تثيح لأولياء الأمور وللطلبة الفرصة للإعراب عن آرائهم بشان نوعية مدارسهم. وتزود البيانات

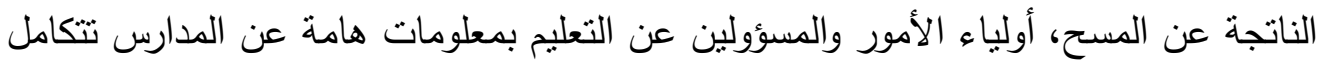

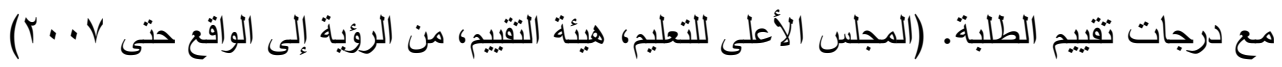

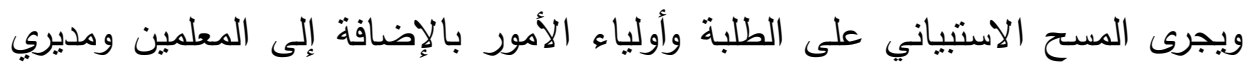

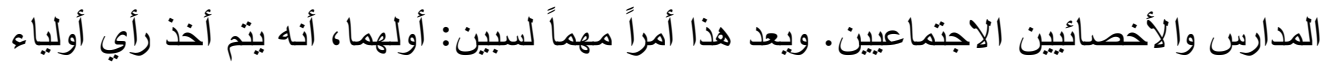

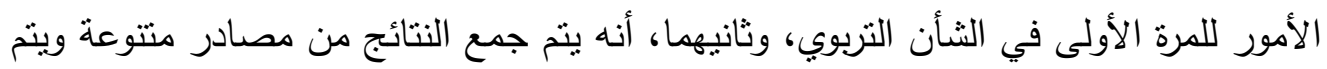

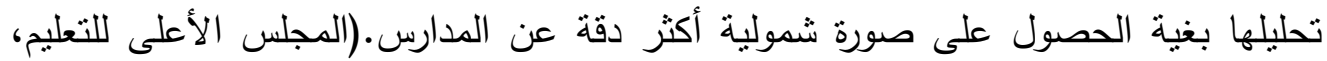

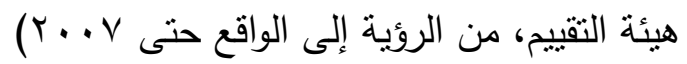

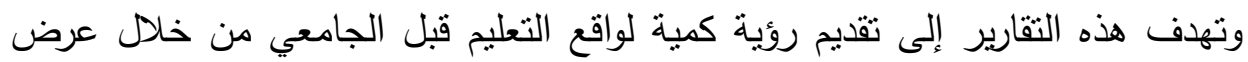

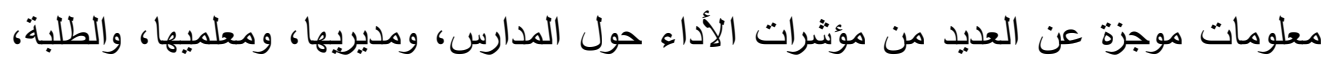

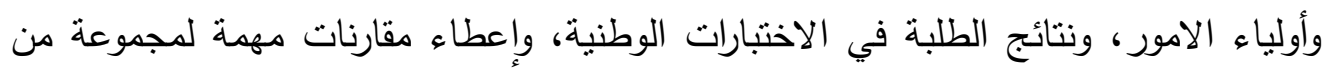

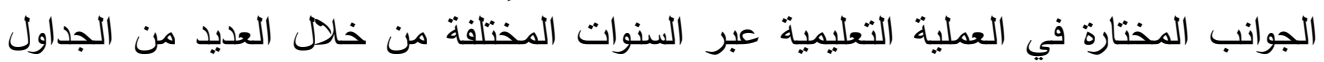

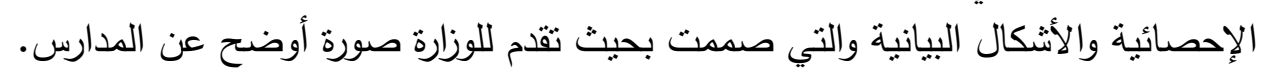

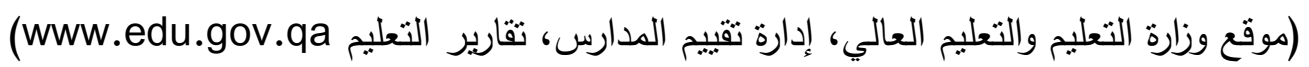

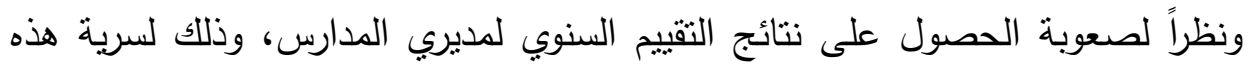

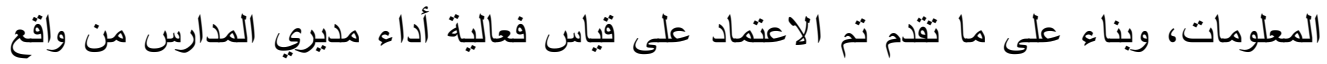

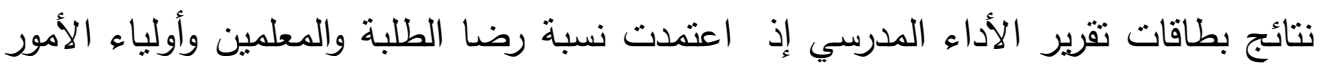

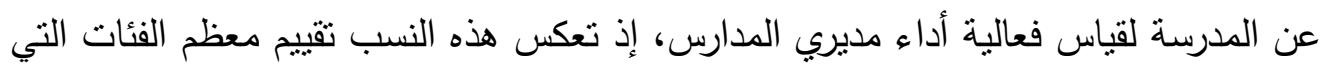
تتعامل مع مدير المدرسة. وعليه، فإن هذه الدراسة تبنت مقياس فعالية أداء مدير المدرسة بحصول المدرسة التي

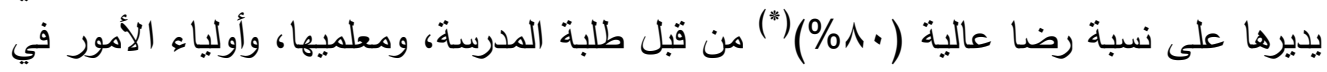

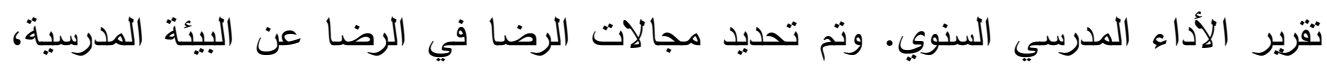

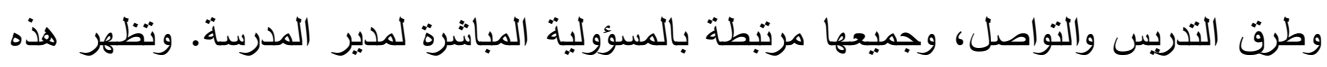

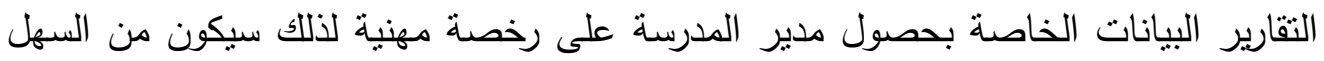

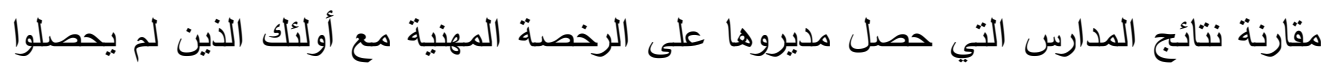
عليها.

تم اختيار نسبة . ^^\% كنقطة مرجعية باعتبار هذه النسبة هي المستوى المقبول لتحقق الأداء والمعمول به

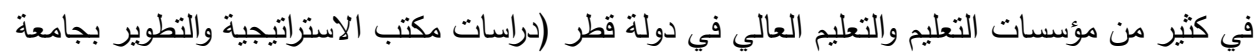

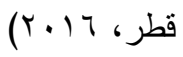


ولقد نوققت هيئة التعليم عن إصدار تقارير أداء المدارس وذلك نظراً للتغييرات العديدة

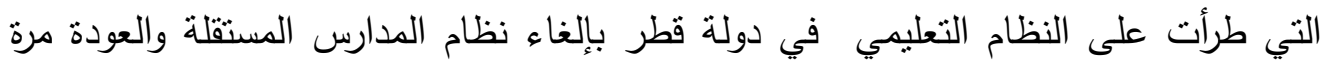

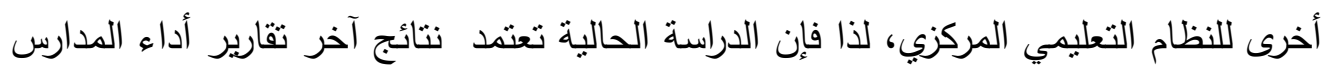

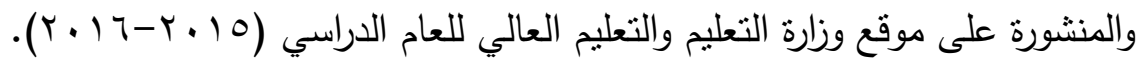

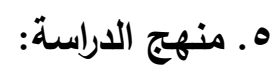

تستخدم الدراسة الحالية المنهج الوصفي التحليلي في بحث العلاقة بين فعالية أداء مديري المدارس وحصولهم على الرخص المهنية. ونم استخدم النسب المئوية والانحراف المعياري بالإضافة إلى اختبار (ت) لمعرفة دلالة الفروق بين المتوسطات.

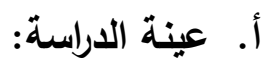

تم اختيار عينة عشوائية من المدارس الحكومية القطرية من الموقع العام لوزارة التعليم

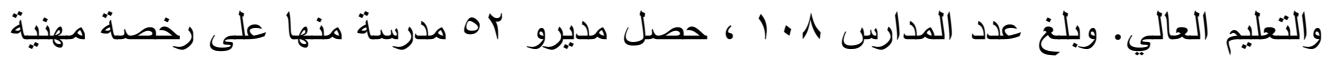

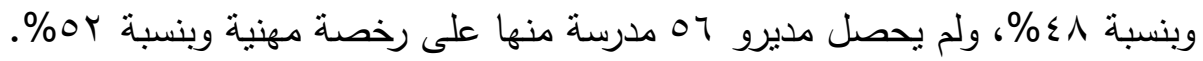
ويوضح الجدول (1) عدد الددارس التي حصل مديروها على رخص مده مهنية ونسبها

مقارنة بتلك التي لم يحصل مديروها على رخص مهنية.

جدول (1)

أعداد مديري المدارس ونسبهم موزعين على المراحل التعليمية وفقاً للرخصة المهنية

\begin{tabular}{|c|c|c|c|c|}
\hline النسبة\% & عدصلوا على ريرين الذين لم & النسبة\%\% & 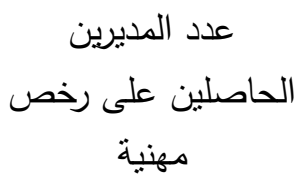 & المرحلة التعليمية \\
\hline$\varepsilon V .0$ & 19 & Or.o & YI & ابتدائي \\
\hline $0 .$. & 11 & $0 .$. & 11 & إعدادي \\
\hline 09.5 & 19 & $\varepsilon \cdot .7$ & IT & ثانوي \\
\hline 01.9 & 07 & $\leq \wedge .1$ & or & المجموع \\
\hline
\end{tabular}

7. الو نتائج الدراسة وتفسيرها

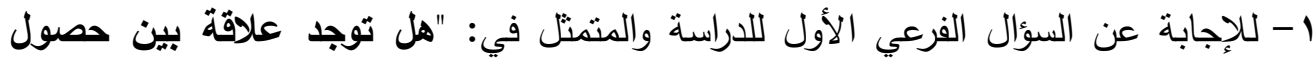
مديري المدارس الحكومية على رخصة مهنية ورضا الطلبة عن المدرسةب؟" فقد تم تحليل

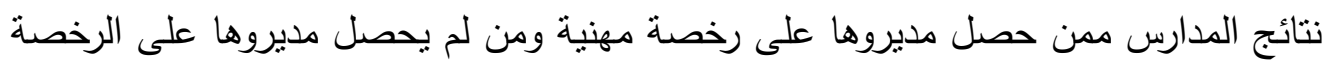

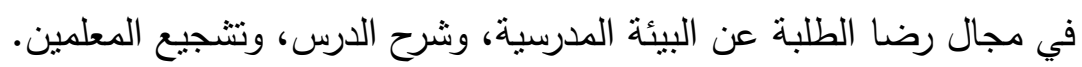




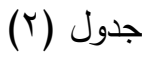

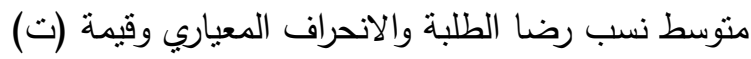

للمدارس التي حصل مديروها على رخصة مهنية والذين لم يحصلوا عليها

\begin{tabular}{|c|c|c|c|c|c|c|c|}
\hline مستوى الدلالة & الحرية & قاتمة & الالحراف & متوسط الرضا & المدارس عدد & المدير على رحول & العناصر \\
\hline \multirow{2}{*}{.$\wedge V 7$} & \multirow{2}{*}{$9 V$} & \multirow{2}{*}{. .107} & $1 . . r M q$ & $V_{\mu} \cdot{ }^{\prime}$ & 0. & نعم & \multirow{2}{*}{ رضيا الطلبة عن البيئة المدرسة } \\
\hline & & & Ir.r.v & $V \Gamma . \varepsilon l$ & $\varepsilon q$ & $\gamma$ & \\
\hline \multirow{2}{*}{$. r \leqslant r$} & \multirow{2}{*}{91} & \multirow{2}{*}{. .900} & $1 . r .0$ & VV.rq & 01 & نعم & \multirow{2}{*}{ شرح الدرس الطلبة عن } \\
\hline & & & Ir.Ir. & V0.1 & $\leqslant 9$ & ע & \\
\hline \multirow[t]{2}{*}{.VYT } & \multirow[t]{2}{*}{91} & \multirow{2}{*}{$\begin{array}{c}. .101 \\
-\end{array}$} & 9.719 & vo.q. & 01 & نعم & \multirow{2}{*}{ تتجيع المعلمين } \\
\hline & & & 11.790 & $V 7.70$ & $\varepsilon 9$ & $y$ & \\
\hline
\end{tabular}

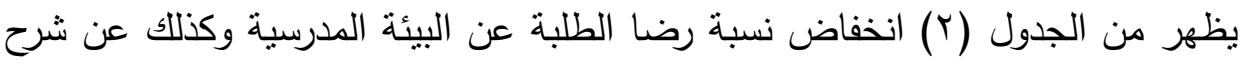

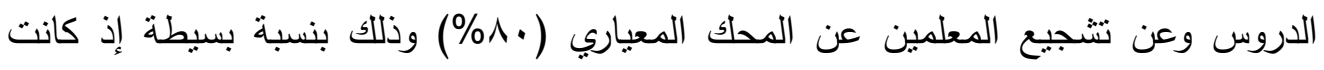

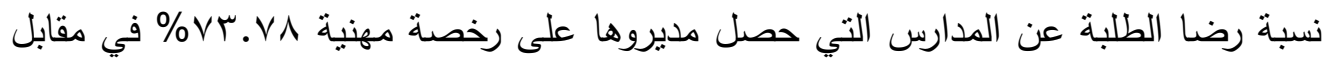

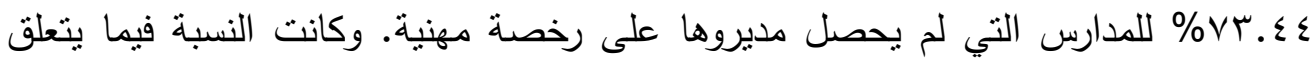

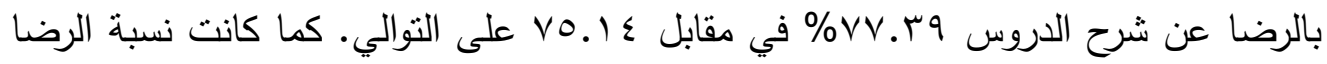

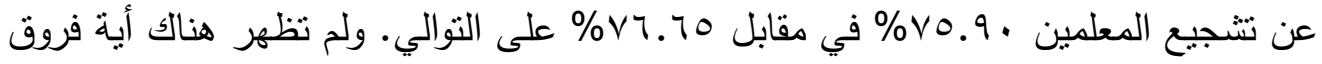
ذات دلالة إحصائية بين نسبة رضا الطلبة في الددارس التي حصل مدير فيروها على على رخصة

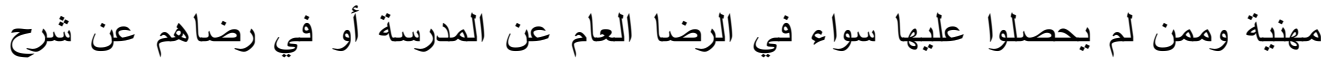

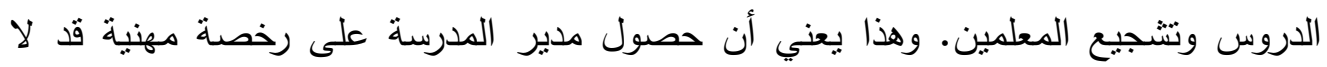

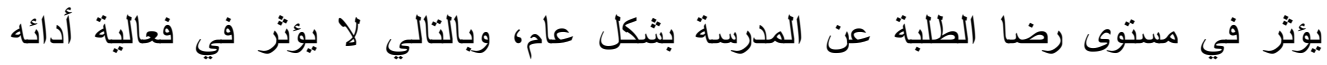

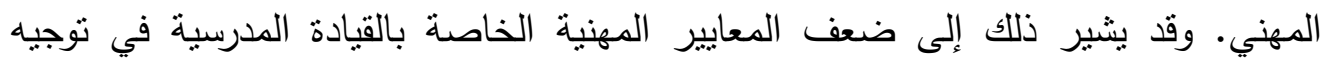

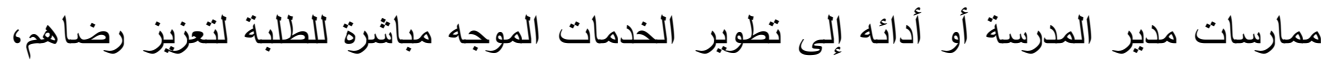

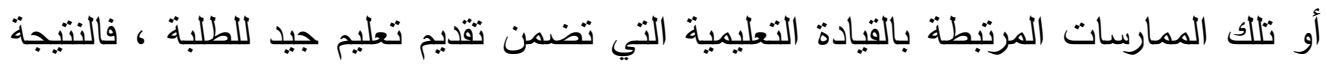
تشير إلى توسط رضا الطلبة عن شرح المعلمين وتشجيعهم.

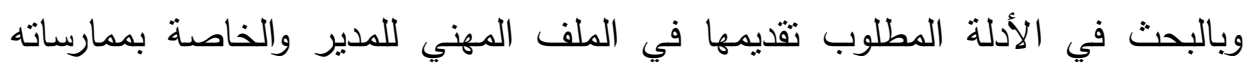

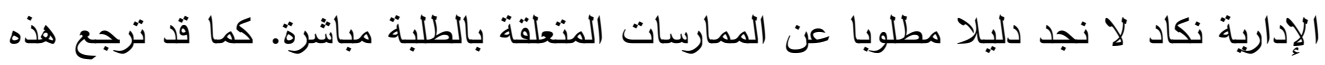

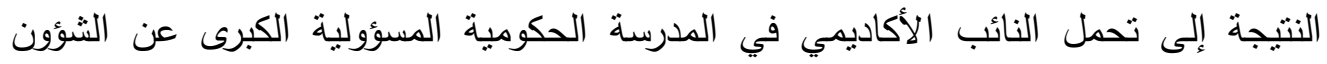

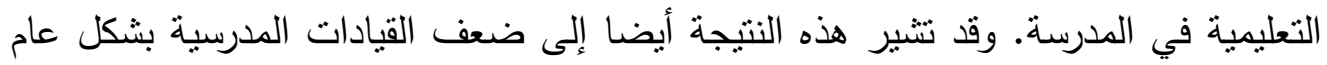

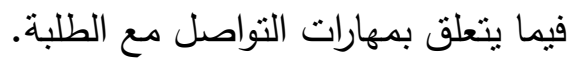


r- ولإجابة على السؤال الثاني والمتمنل في: "هل توجد علاقة بين حصول مديري المدارس

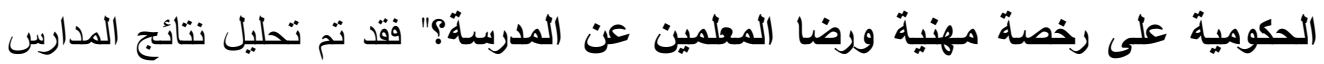

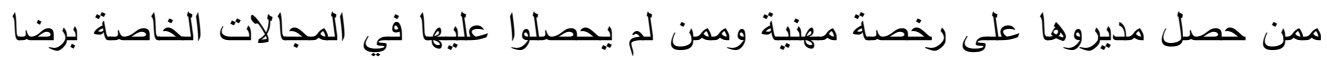
المعلمين عن البيئة المدرسية والمشاركة في صنع القرارات، كما ينضح في الجدول النالي:

$$
\text { جدول (r) }
$$

متوسط نسب رضا المعلمين والانحراف المعياري وقيمة (ت)

للمدارس التي حصل مديروها على رخصة مهنية والذين لم يحصلوا عليها

\begin{tabular}{|c|c|c|c|c|c|c|c|}
\hline مستوى الدلالة & الحرية & قيمة & الالنحراف & متوسط & المدارس & رخصدة مهنير على & العناصر \\
\hline \multirow{2}{*}{$\because \ldots \leqslant 0$} & \multirow{2}{*}{$1 \ldots$} & \multirow{2}{*}{ r..r. } & T.VI & qY. $\leqslant 1$ & Or & نعم & \multirow{2}{*}{ رضيأ المعلمين عن المدرسية } \\
\hline & & & $1 \% .0 \mathrm{VA}$ & $\Lambda \Lambda . Y$. & 0. & $\bar{y}$ & \\
\hline \multirow[b]{2}{*}{$" \ldots \leq 0$} & \multirow[b]{2}{*}{$1 \ldots$} & \multirow[b]{2}{*}{ r.. Tr } & $1 \cdot V \cdot r$ & V..rr & Or & نعم & \multirow{2}{*}{ فن المشاركة المعلمين } \\
\hline & & & $9.00 \leqslant$ & $77 . Y \leq$ & 0 . & $y$ & \\
\hline
\end{tabular}

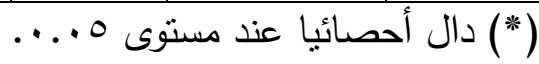

تظهر النتائج أن متوسط نسبة رضا معلمي المدارس التي يمتلك مديروها رخصا مهنية عن البيئة المدرسية كان أعلى من منوسط نسبة رضا معلمي المدارس التي لا يملك مديروها

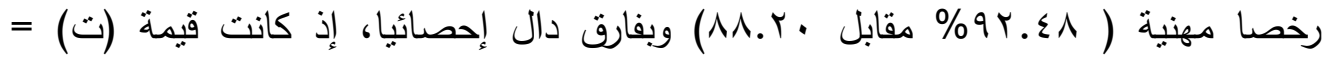

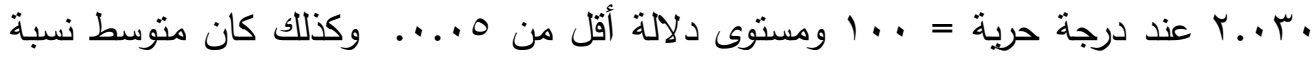

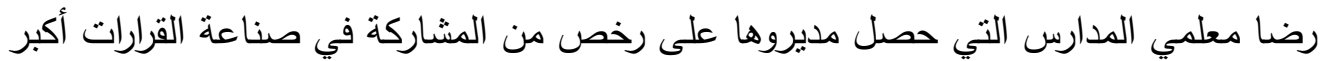

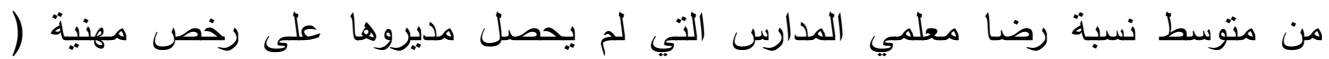

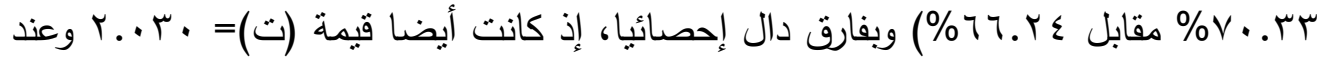

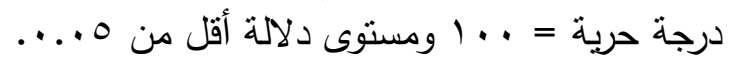

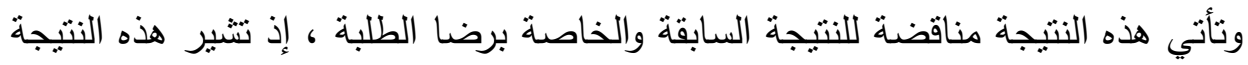

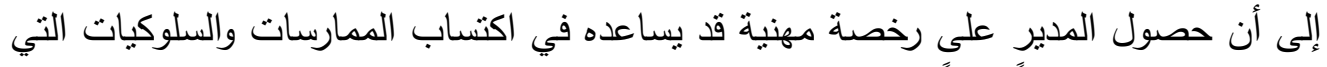

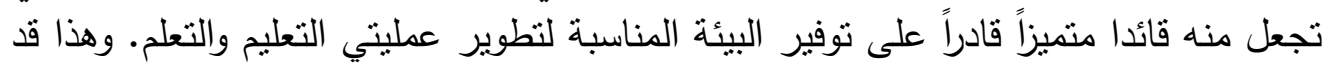

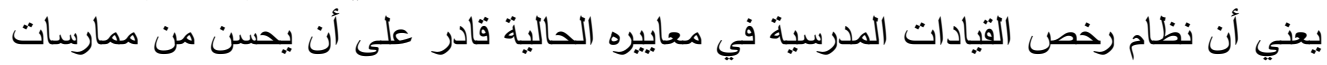

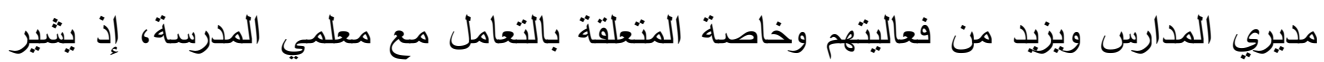

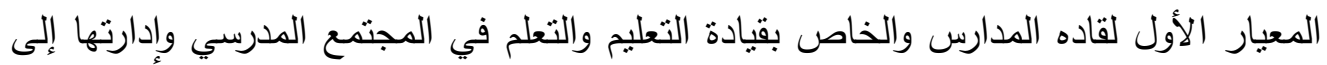

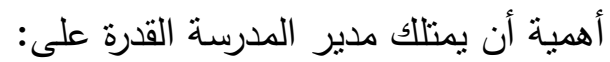
- تهيئة بيئة تعلم آمنة ومثمرة ومثيرة للتحدي في المدرسة بأكملها وتعزيزها والمحافظة عليها. 
- قيادة السياسات المدرسية والاستراتيجية والتأثير فيها من خلال منهجية المدرسة ككل.

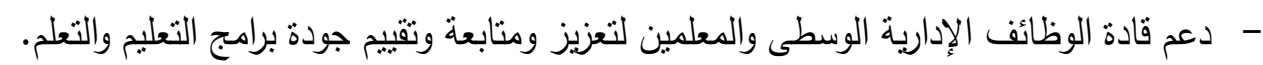

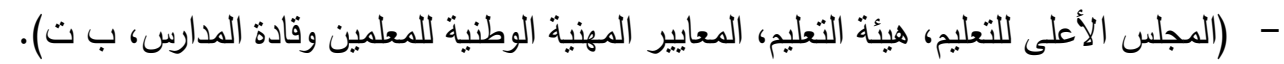

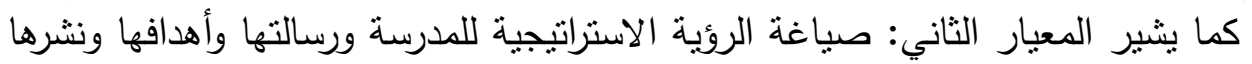

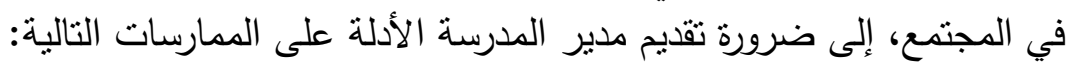
- التواصل بشأن الروئية لإثارة التحدي لدئ الدير المعلمين ومجتمع المدرسة. - - - التواصل بشأن التوقعات العالية.

- توثيق التخطيط المتشعب الاستراتيجي للقاءات دورية مع المعلمين على مستوى المدرسة.

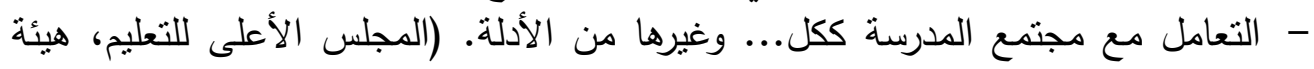

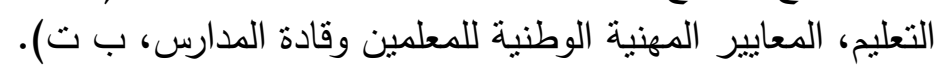

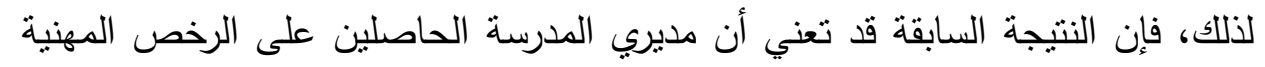

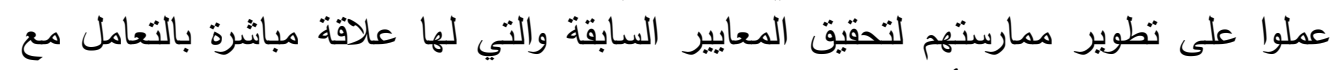

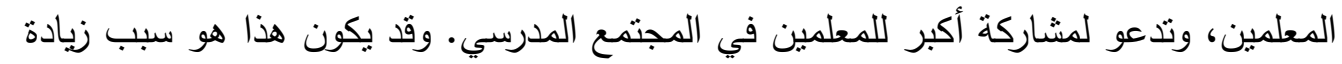
رضاهم عن المدرسة بشكل عام.

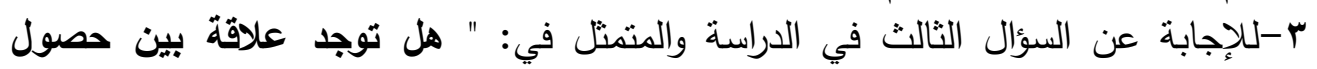

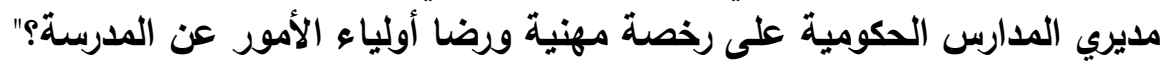

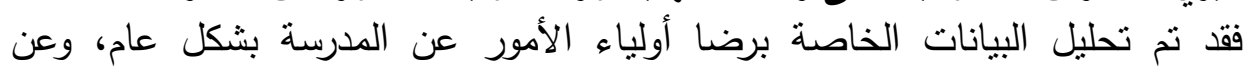

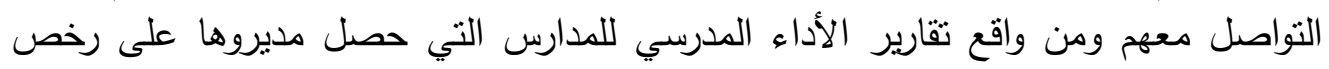

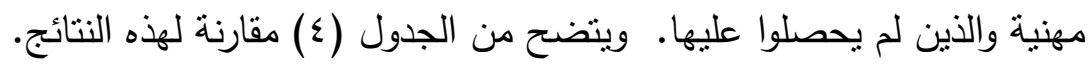

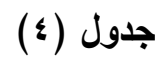

متوسط نسب رضا أولياء الأمور عن المدرسة والتواصل معهم بالنسبة للمدارس التي حصل مديروها

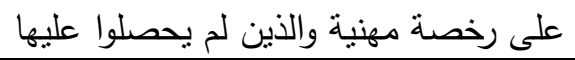

\begin{tabular}{|c|c|c|c|c|c|c|c|}
\hline مستوى الدلالة & الحربة & 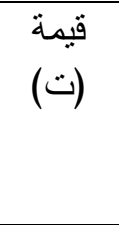 & المعياري & متوسط & المدارس & رحصنية & العناصر \\
\hline \multirow{2}{*}{$\cdots$} & \multirow{2}{*}{99} & \multirow{2}{*}{$1.17 r$} & $\mid Y_{.} \cdot 11$ & $\begin{array}{c}A r . r \\
0\end{array}$ & 01 & نعم & \multirow{2}{*}{ الأمور عن أولياء } \\
\hline & & & rq.० $\leqslant V$ & $\begin{array}{c}r \varepsilon . q \\
\wedge\end{array}$ & 0. & $y$ & \\
\hline \multirow{2}{*}{$\cdots$} & \multirow{2}{*}{99} & \multirow{2}{*}{1.797} & $7.0 \mathrm{~V} \varepsilon$ & $\begin{array}{c}V 4 . \Lambda \\
\varepsilon\end{array}$ & 0. & نعم & \multirow{2}{*}{ الأمور عن أولياء } \\
\hline & & & $\Gamma \varepsilon . \wedge V \varepsilon$ & $\begin{array}{c}r r . t \\
r\end{array}$ & 01 & $y$ & \\
\hline
\end{tabular}

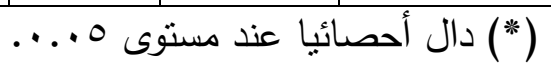


تظهر النتائج أن نسبة رضا أولياء أمور الطلبة التي يمنلك مديروها رخصا مهنية أعلى مئى

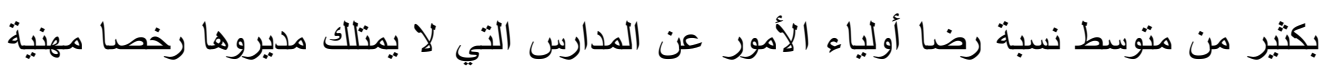

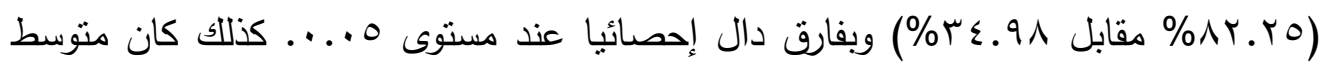

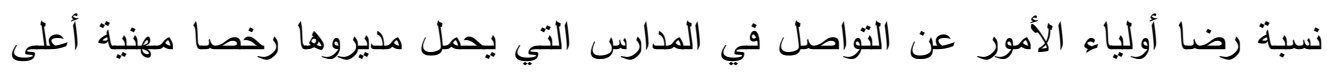

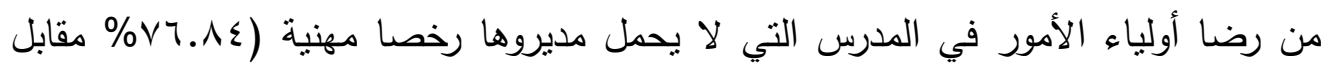

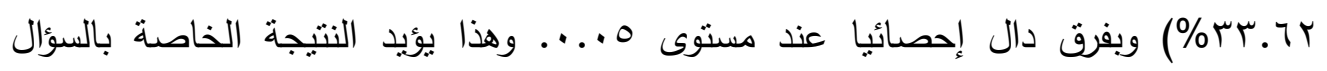

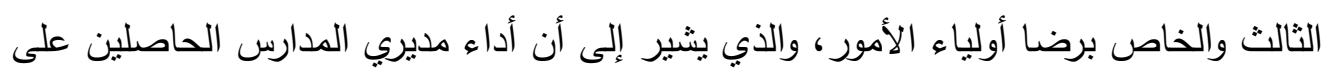

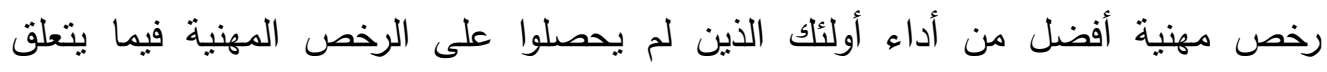

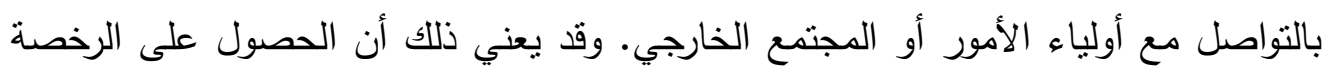
المهنية يزيد من فعالية أداء مدير المدرسة.

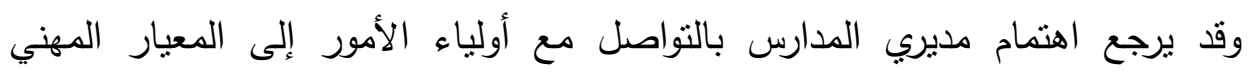

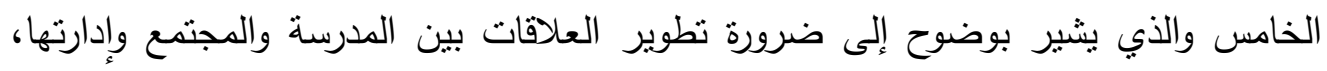

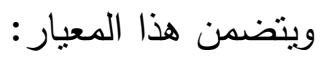

- بناء علاقات إيجابية مع الأسر لتعزيز تعلم الطلبة. - تأسيس علاقات شراكة بين المجتمع والمدرسة لتعزيز تعلم الطلبة. - النواصل بشكل فاعل مع المجتمع المدرسي. (المجلس الأعلى للتعليم، هيئة التعليم، المعايير المهنية الوطنية للمعلمين وقادئ

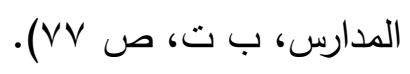

ويستدعي هذا المعيار من مدير المدرسة ضروره نوفير عينات من الأدلة عن الممارسة التالية:

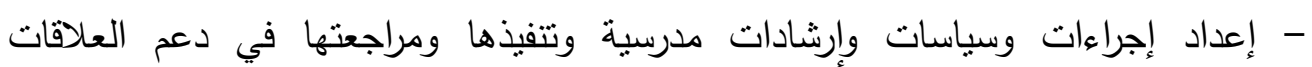
الإيجابية والتواصل الفاعل مع الأسر والمجتمع المدرسي.

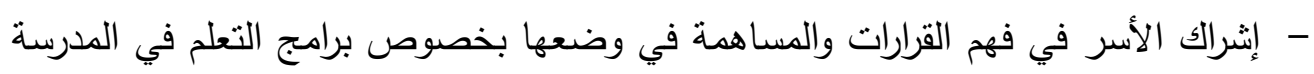
وعملياتها وبرامجها. - بناء قدرات المجموعات الرئيسة مثل مجلس الأمناء (الذي يضم ممنلين عن أولياء

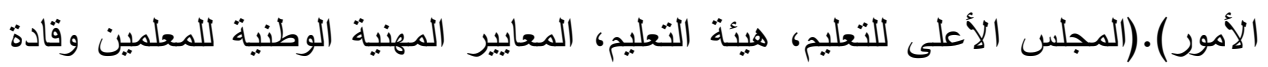

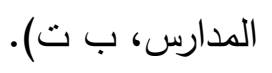

ولا شك أن ممارسة هذه السلوكيات التربوية ستتعكس إيجابا على طريقة وأساليب وجودة التواصل مع أولياء الأمور وزيادة فعالية أداء مدير المدرسة فيما يخص هذات هذا الجانب. 


\section{V. توصيات ومقترحات}

نتيجة للتحديات التي واجهت تطبيق نظام الرخص المهنية في قطر، فقد قرر المجلس

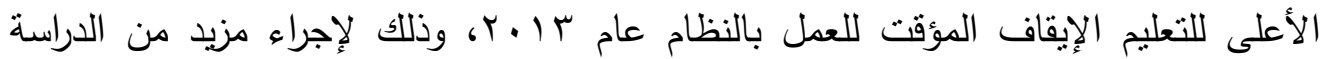

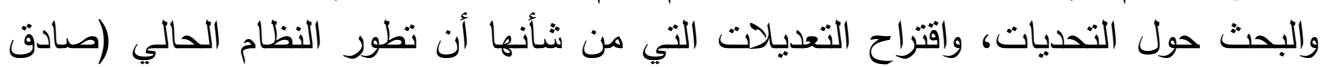

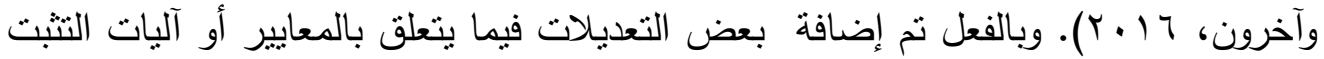

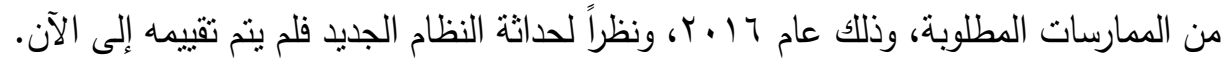

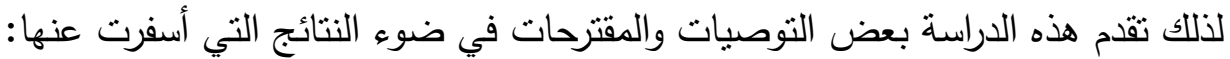

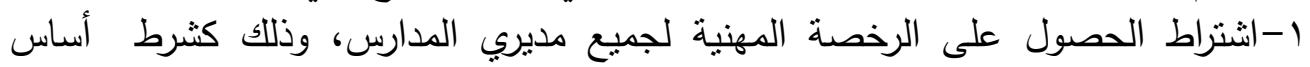

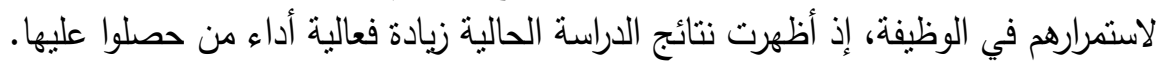

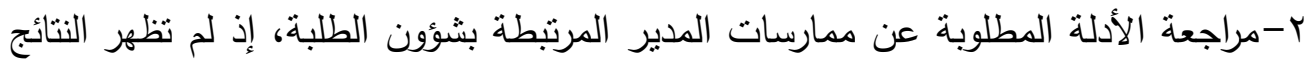

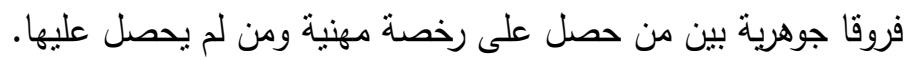

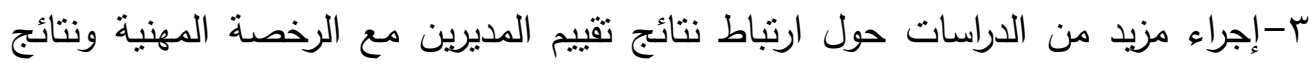
بطاقات تقرير الأداء المدرسي. ع-تنظيم دورات تدريبية للمديرين حول تحليل نتائج تقييم الأداء المدرسي وطريقة الاستفادة

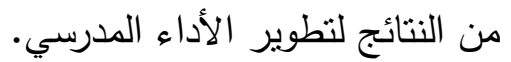

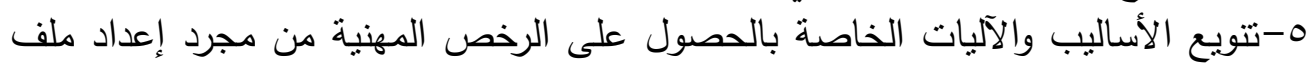

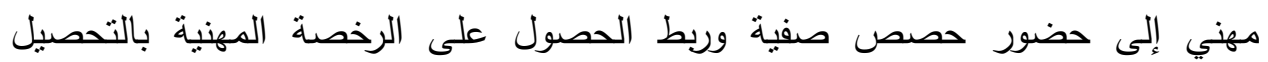
الأكاديمي للطلبة. 


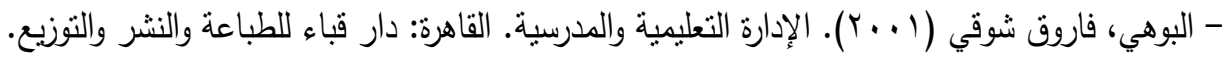

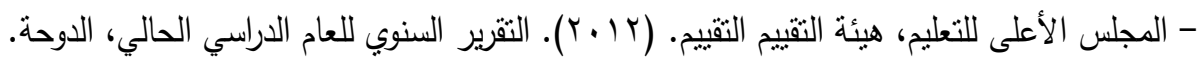
- المجلس الأعلى للتعليم، هيئة التقبيم. (11 ـ (1). سياسات الرخص المهنية للمعلمين وقادة المدارس، الدوحة.

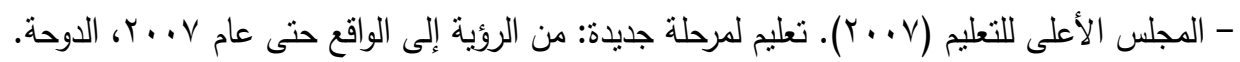
- المجلس الأعلى للتعليم، هيئة التعليم، المعايير المهنية الوطنية للمعلمين وقادة المدارس في دولة

$$
\text { قطر (ب ت). الدوحة. }
$$

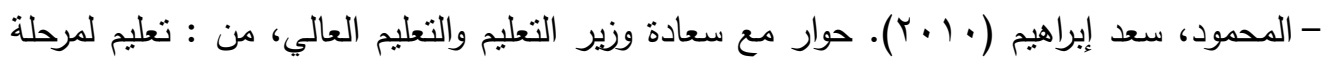

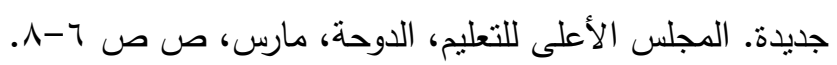

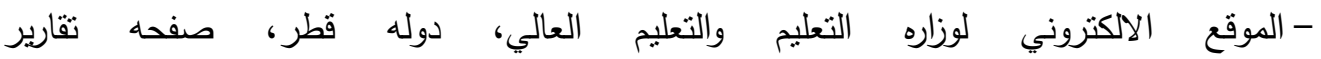
التعليم www.edu.gov.qa.

- جامعة قطر (7 1 • Y). دراسات مكتب الاستراتيجية والتطوير بجامعة قطر . الدوحة.

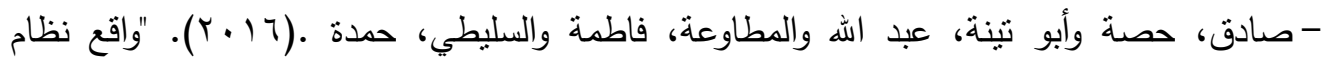
الرخص المهنية للمعلمين في دولة قطر". المجلة التربوية الدولية المتخصصة، المجلد

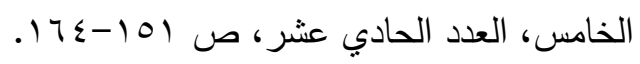

- مارزانو، ووترز وماكنلتي (9 . . r). القيادة المدرسية الناجحة: من البحوث إلى النتائج. الرياض: العبيكان. - يعقوب، سهيل (1 (. - م). الإدارة المدرسية في لبنان: مشكلاته وحلول مقترحة من: الإدارة التربوية

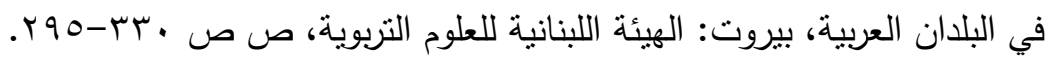

- Bottoms, G., \& O'Neill, K. (2001). Preparing a New Breed of School Pnincipals: It's Time for Action. Southern Regional Education Board, atlanta, GA.

- Davis, S., Darling - Hammond, L., Lapointe, M. \& Meyerson, D. (2005). Developing Successful Principal. Stanford Educational Leadership Institnte, Ed. Retrieved February, 20, 2009.

- Cherif, M., Romanowski, M. \& Nasser, R. (2012). All that Glitters is not Gold: Challenges of Teacher and School Leader Licensure Licensing System in Qatar. International Journal of Educational Development, 32 (3), 471-48. 
- Grissom, J. A., \& Loebs, S. (2011). Triangulatiog Princpal Effectivenes: How Perspectives of Parents, Teachers, and Assistant Principal: Identify the Central Importance of Managerial Skills. American Educational Research Journal, 48 (5), 1091-1123.

- Hess, F. M. (2003). A Liconse to Lead? A new Leadership Agenda for Amercas Schools. Progressive Policy Institute, Pennnsylvania Ave.

- Hess. F. M. \& Kelly, A.P. (2007). Learning to Lead: What Gets Taught in Principal-Preparation Programs. Teacher College Recond, 09 (1), 244-274. 